\title{
Energy Transfer from Fluorene Based Conjugated Polyelectrolytes to On-chain and Self-Assembled Porphyrin Units
}

\begin{tabular}{|r|l|}
\hline Journal: & J. Polym Sci. Part A: Polym. Chem. \\
\hline Manuscript ID: & JPOL-A-11-0953.R1 \\
\hline Wiley - Manuscript type: & Original Article \\
\hline Keywords: & $\begin{array}{l}\text { conjugated polymers }<\text { C, self-assembly }<\text { S, hydrophilic polymers }<\text { H, } \\
\text { fluorescence }<\text { F, water-soluble polymers }<\text { W }\end{array}$ \\
\hline \multicolumn{2}{|l}{}
\end{tabular}

SCHOLARONE ${ }^{m}$

Manuscripts 
Table 1.

\begin{tabular}{|c|c|c|c|c|}
\hline Solvent & $\begin{array}{l}\text { Absorption } \\
\max (\mathrm{nm})\end{array}$ & $\begin{array}{l}\text { Emission } \\
\max (\mathrm{nm})\end{array}$ & $\begin{array}{c}\Phi_{\mathrm{F}} \mathrm{PF} \\
\lambda_{\mathrm{exc}} 362(\mathrm{~nm})\end{array}$ & $\begin{array}{c}\Phi_{\mathrm{F}} \mathrm{DPP} \\
\lambda_{\mathrm{exc}} 362(\mathrm{~nm})\end{array}$ \\
\hline $\begin{array}{l}\text { Dioxane } \\
(1: 1)\end{array}$ & $\begin{array}{l}365,420 \\
(P F, D P P)\end{array}$ & $\begin{array}{l}410,650 \\
(P F, D P P)\end{array}$ & 0.41 & 0.013 \\
\hline $\begin{array}{l}1 \times 10^{-4} \\
\text { aqueous } \mathrm{C}_{12} \mathrm{E}_{5}\end{array}$ & $\begin{array}{l}367,425 \\
\text { (PF, DPP) }\end{array}$ & $\begin{array}{l}411,655 \\
(\mathrm{PF}, \mathrm{DPP})\end{array}$ & 0.34 & 0.017 \\
\hline
\end{tabular}

Table 2.

\begin{tabular}{|c|c|c|c|c|c|c|c|c|c|c|}
\hline & $\begin{array}{l}\lambda_{\text {em }} \\
(\mathrm{nm})\end{array}$ & $\begin{array}{l}\tau_{1} \\
\text { (ns) }\end{array}$ & $\begin{array}{l}\tau_{2} \\
\text { (ns) }\end{array}$ & $\begin{array}{l}\tau_{3} \\
\text { (ns) }\end{array}$ & $\begin{array}{l}\tau_{4} \\
\text { (ns) }\end{array}$ & $\mathbf{a}_{\mathbf{i 1}}$ & $a_{\mathbf{i} 2}$ & $\mathbf{a}_{\mathrm{i} 3}$ & $\mathbf{a}_{\mathbf{i} 4}$ & $\chi^{2}$ \\
\hline \multirow{2}{*}{$\begin{array}{l}\text { Dioxane - } \\
\text { Water } \\
(1: 1)\end{array}$} & 410 & 0.06 & - & 0.55 & - & 0.140 & - & 0.860 & - & 1.05 \\
\hline & 650 & - & 0.13 & 0.61 & 4.87 & - & 0.227 & 0.401 & 0.372 & 0.98 \\
\hline \multirow[t]{2}{*}{$C_{12} E_{5}$} & 410 & 0.05 & - & 0.59 & - & 0.388 & - & 0.612 & - & 1.04 \\
\hline & 650 & - & 0.37 & - & 4.89 & - & 0.366 & - & 0.634 & 0.96 \\
\hline
\end{tabular}

Table 3.

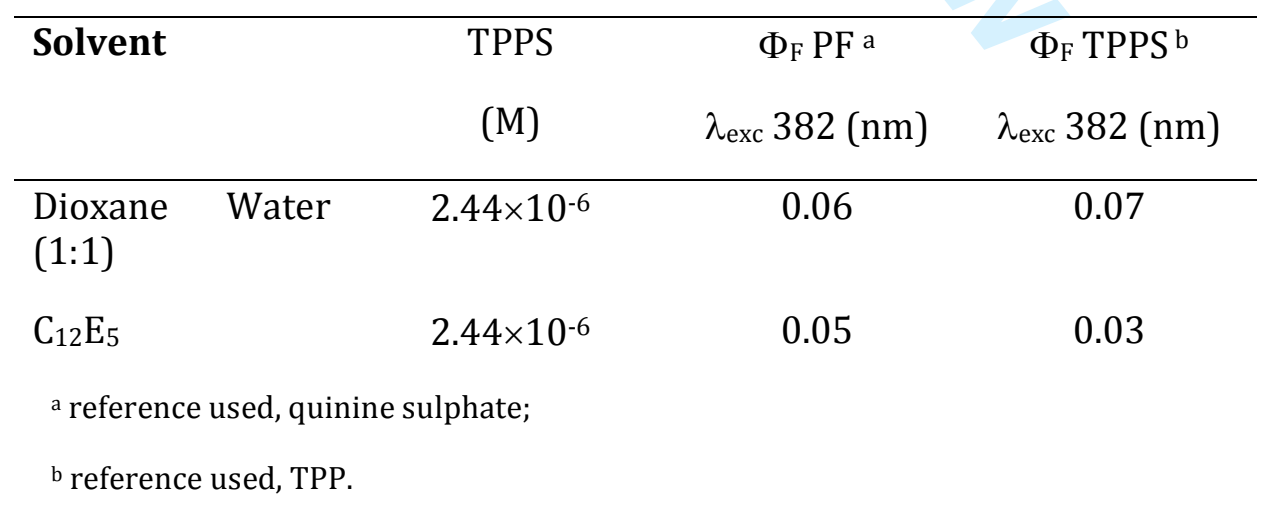


Table 4.

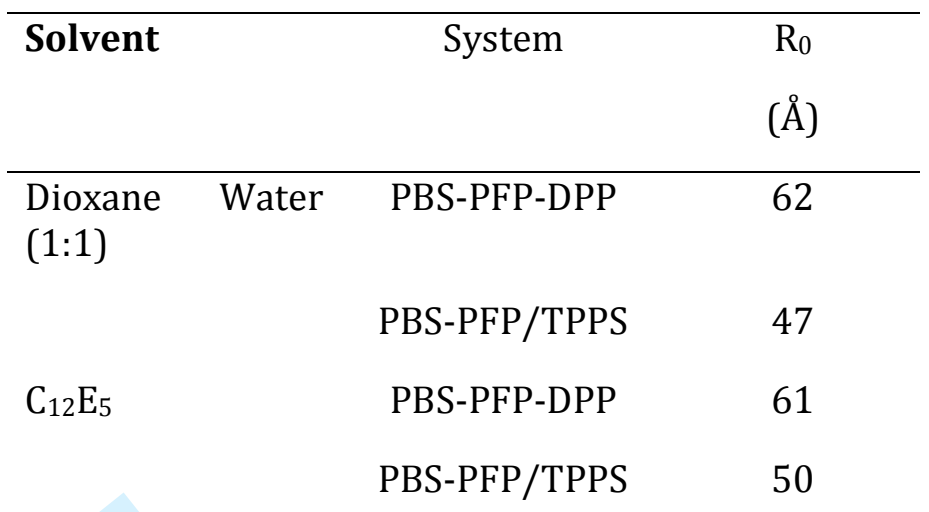




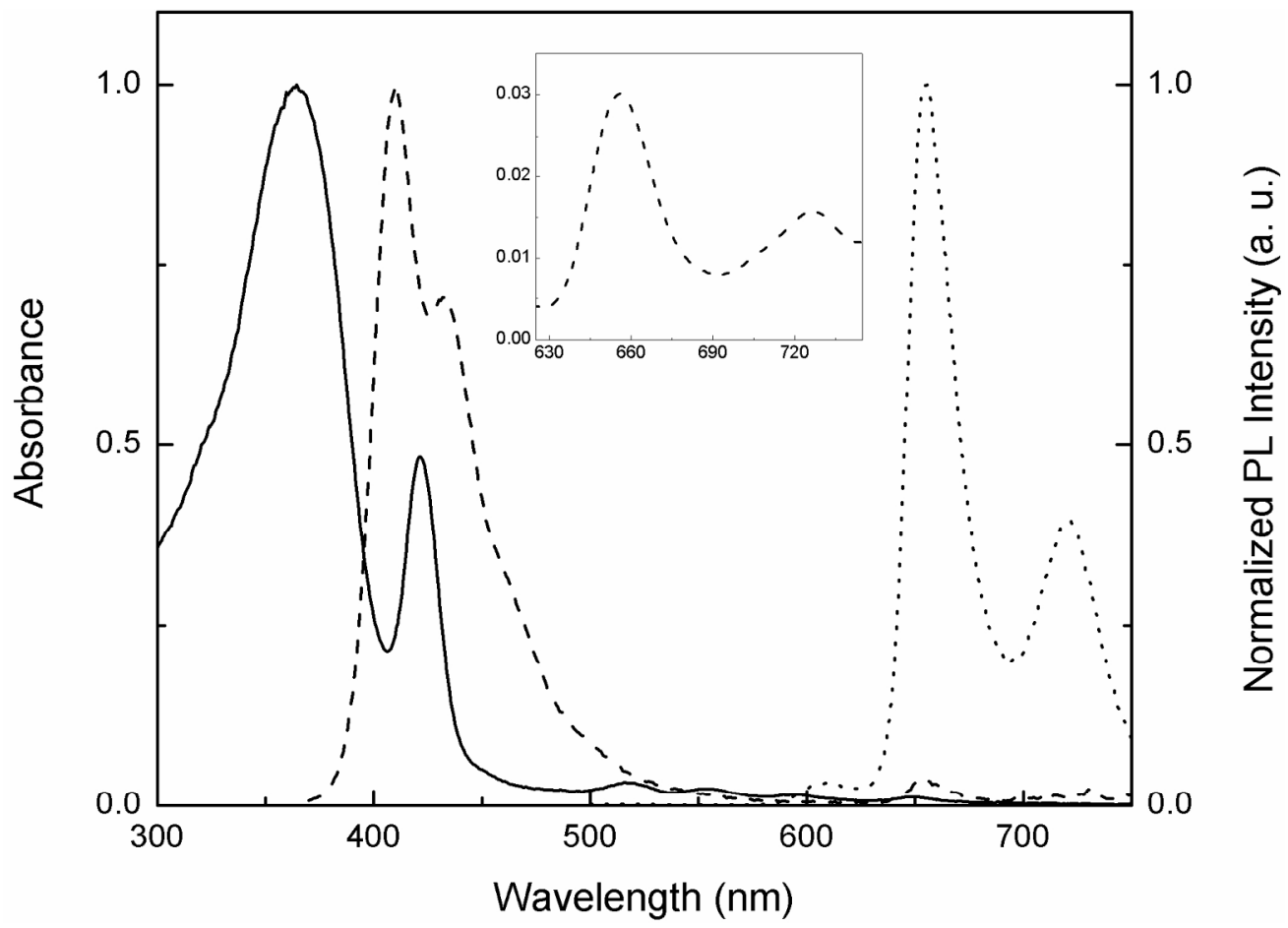

Absorption (solid line) and emission spectra (dashed line) of PBS-PFP-DPP in dioxane-water (1:1), with excitation at $365 \mathrm{~nm}$ (dashed line) and $420 \mathrm{~nm}$ (dotted line). The inset depicts the $600-750 \mathrm{~nm}$ region of the PBS-PFP-DPP emission shown in the main plot.

$177 \times 126 \mathrm{~mm}(300 \times 300 \mathrm{DPI})$ 


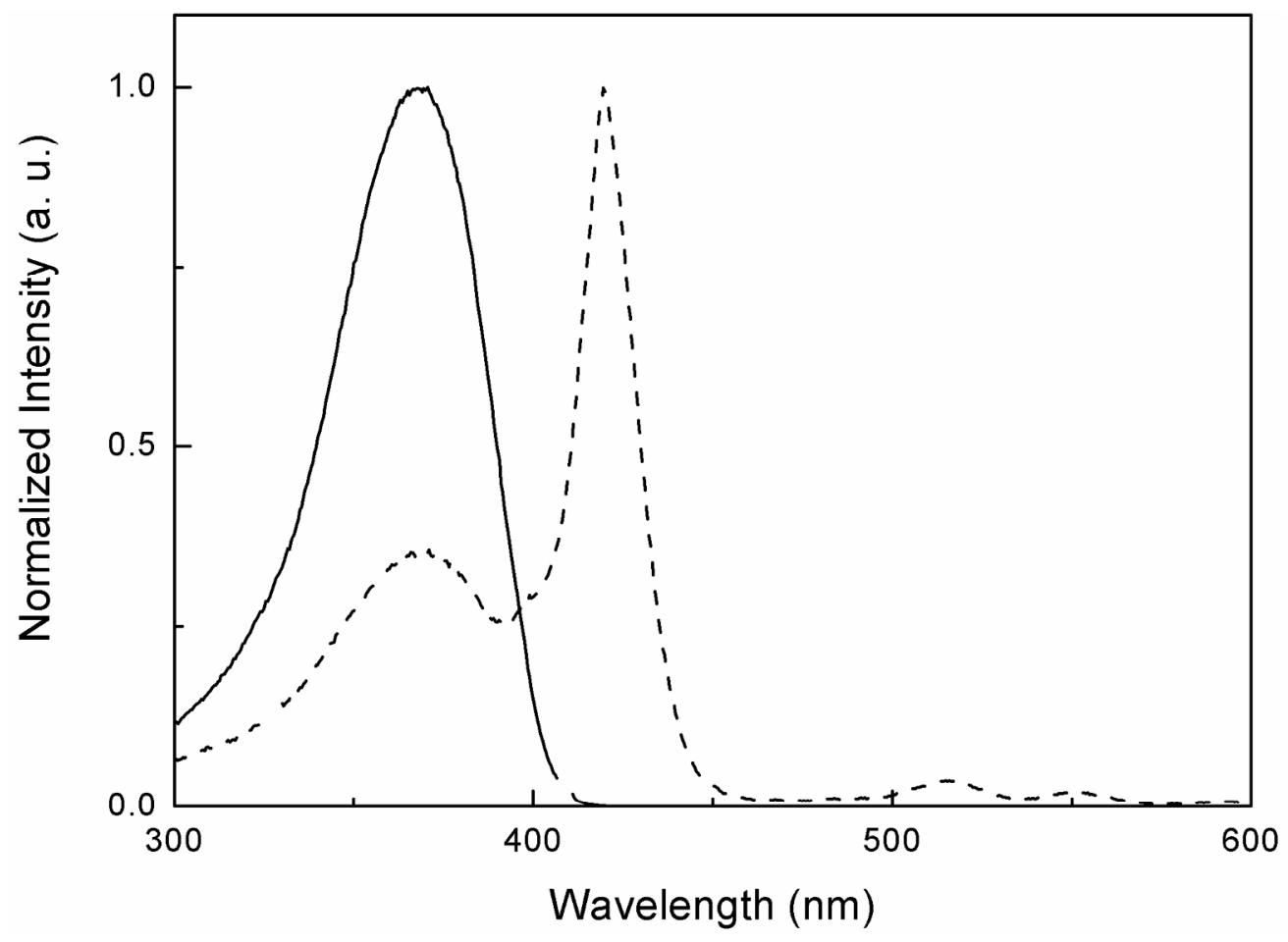

Fluorescence excitation spectra with emission at $410 \mathrm{~nm}$ (solid line) and emission at $655 \mathrm{~nm}$ (dashed line) of PBS-PFP-DPP in dioxane-water $(1: 1)$.

$177 \times 128 \mathrm{~mm}(300 \times 300 \mathrm{DPI})$ 

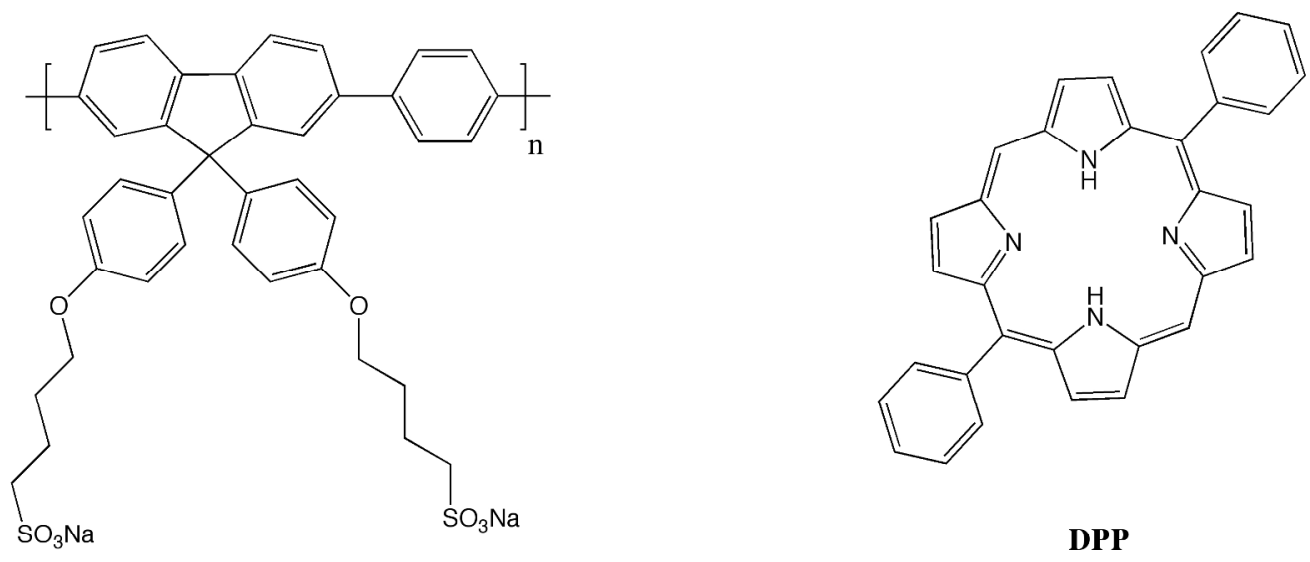

PBS-PFP

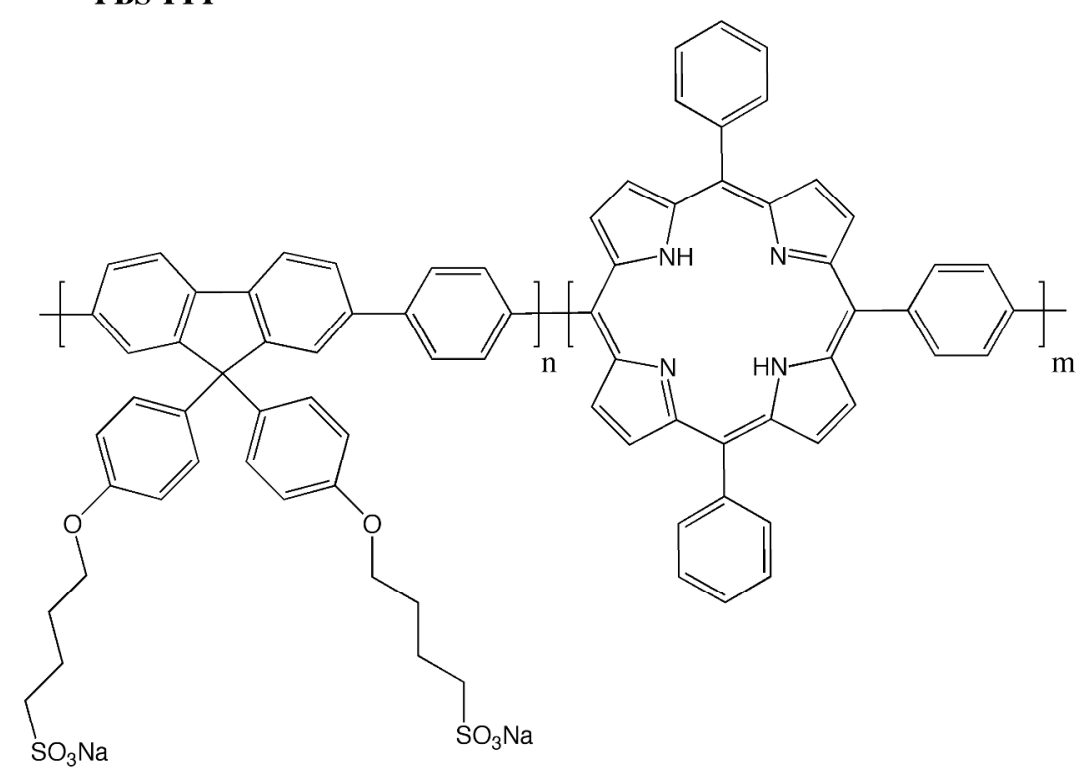

PBS-PFP-DPP

Chemical structures of the homopolymer PBS-PFP, the DPP monomer and the copolymer PBS-PFP-DPP. $260 \times 288 \mathrm{~mm}(300 \times 300 \mathrm{DPI})$ 


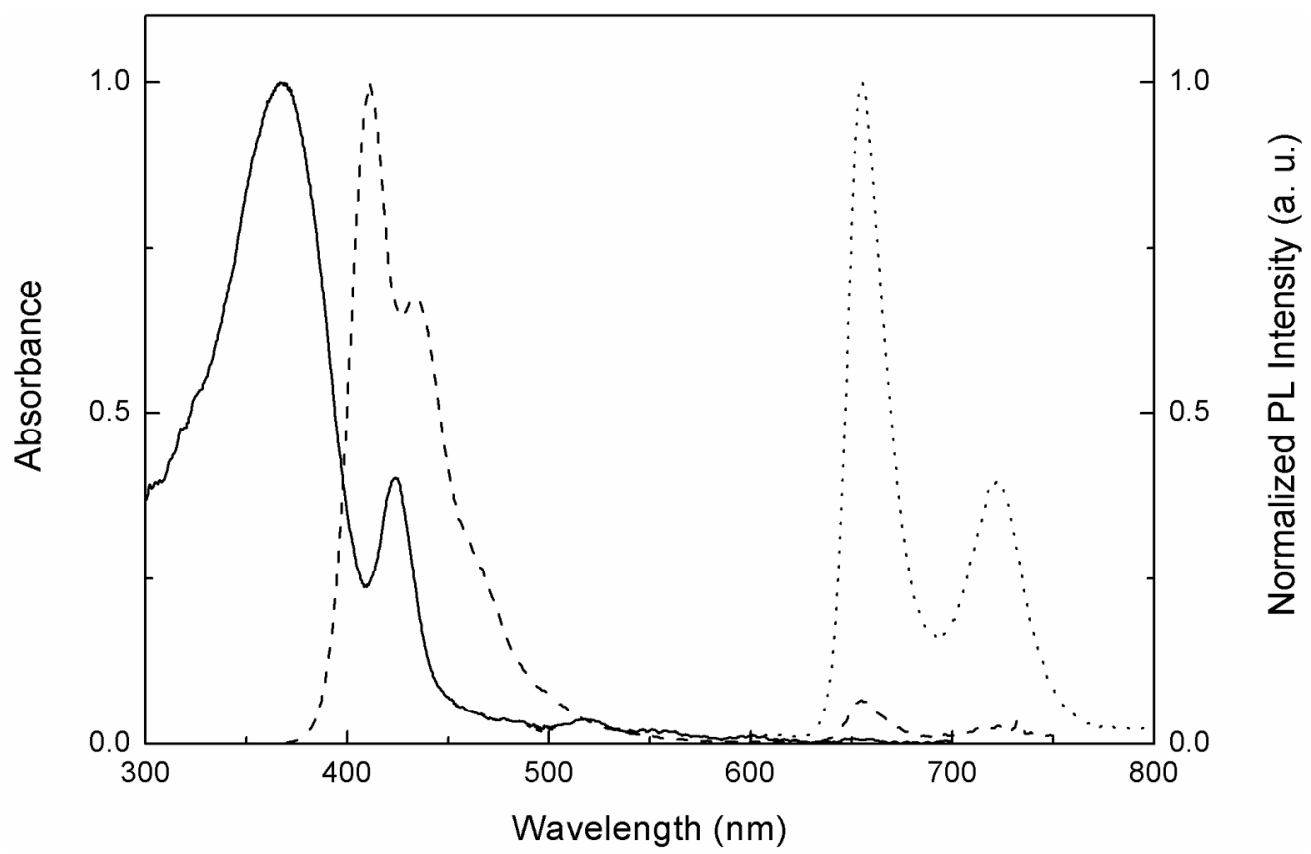

Absorption (solid line) and emission spectra (dashed line) of PBS-PFP-DPP in $1 \times 10-4 \mathrm{M}$ aqueous C12E5 solution, with excitation at $365 \mathrm{~nm}$ (solid line) and $420 \mathrm{~nm}$ (dotted line). $177 \times 114 \mathrm{~mm}(300 \times 300 \mathrm{DPI})$ 


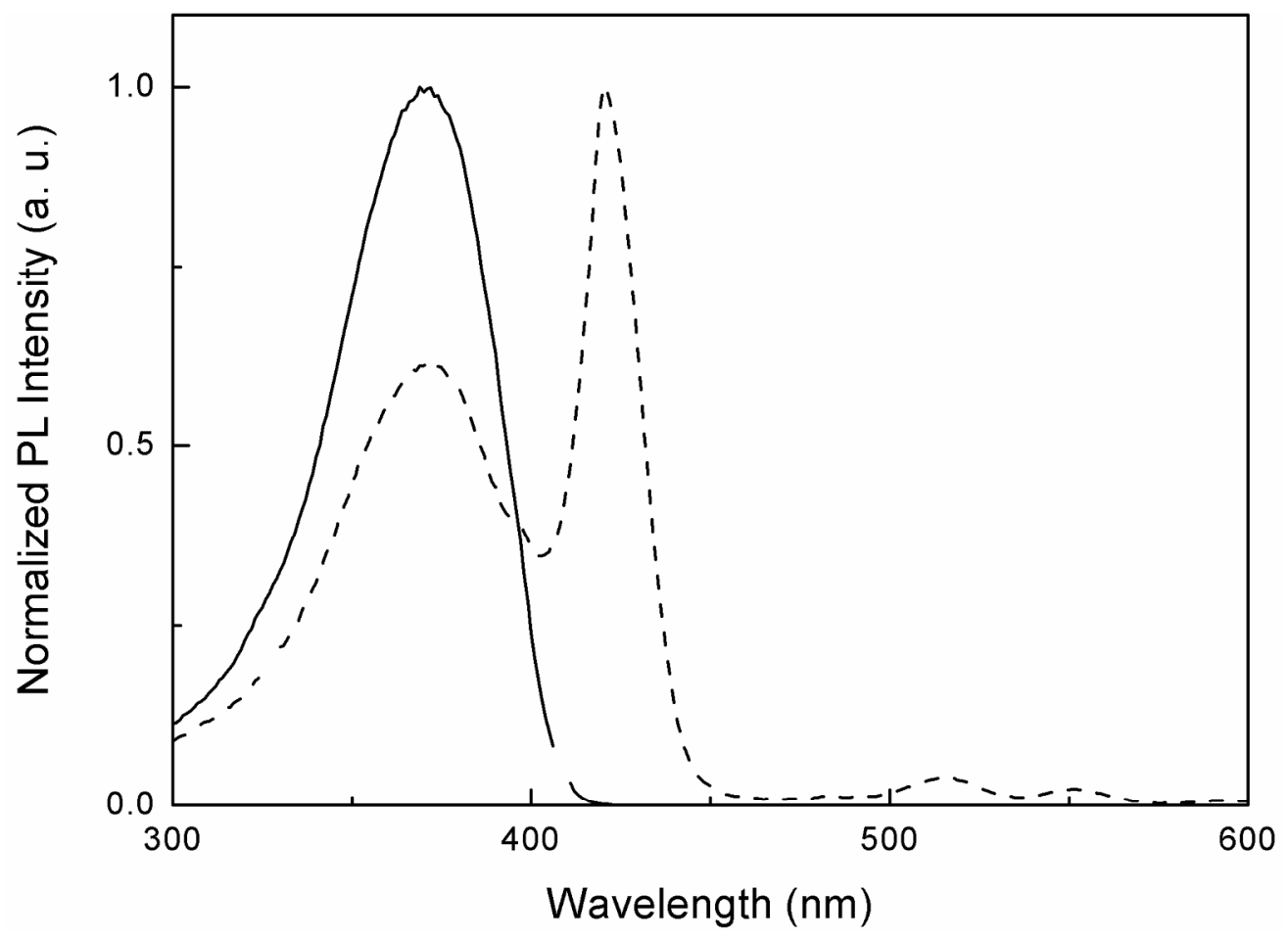

Fluorescence excitation spectra with emission at $410 \mathrm{~nm}$ (solid line) and emission at $655 \mathrm{~nm}$ (dashed line) of PBS-PFP-DPP in $1 \times 10-4 \mathrm{M}$ aqueous C12E5.

$177 \times 128 \mathrm{~mm}(300 \times 300 \mathrm{DPI})$ 


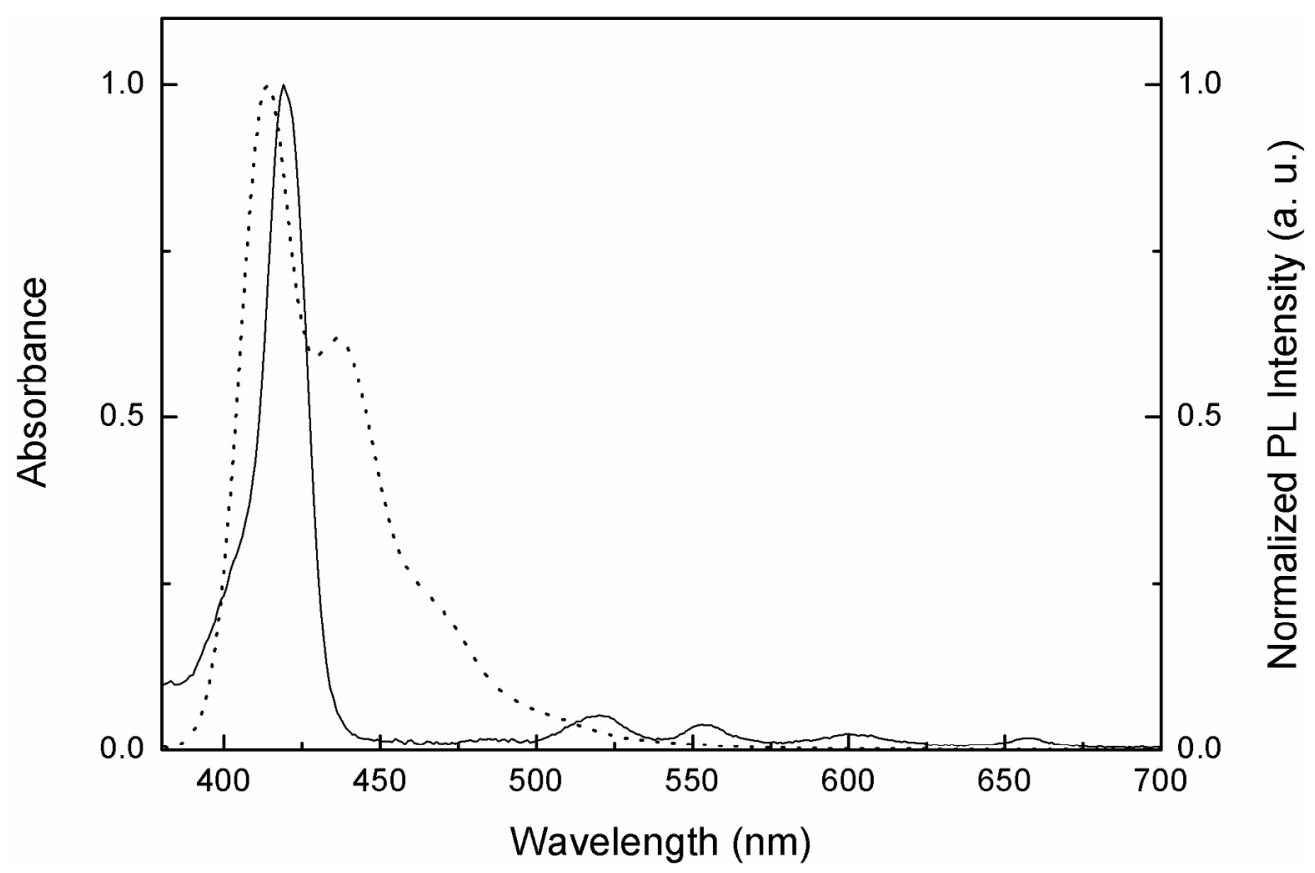

Spectral overlap between the donor PBS-PFP (dotted line) and the acceptor DPP (full line). $177 \times 116 \mathrm{~mm}(300 \times 300 \mathrm{DPI})$ 


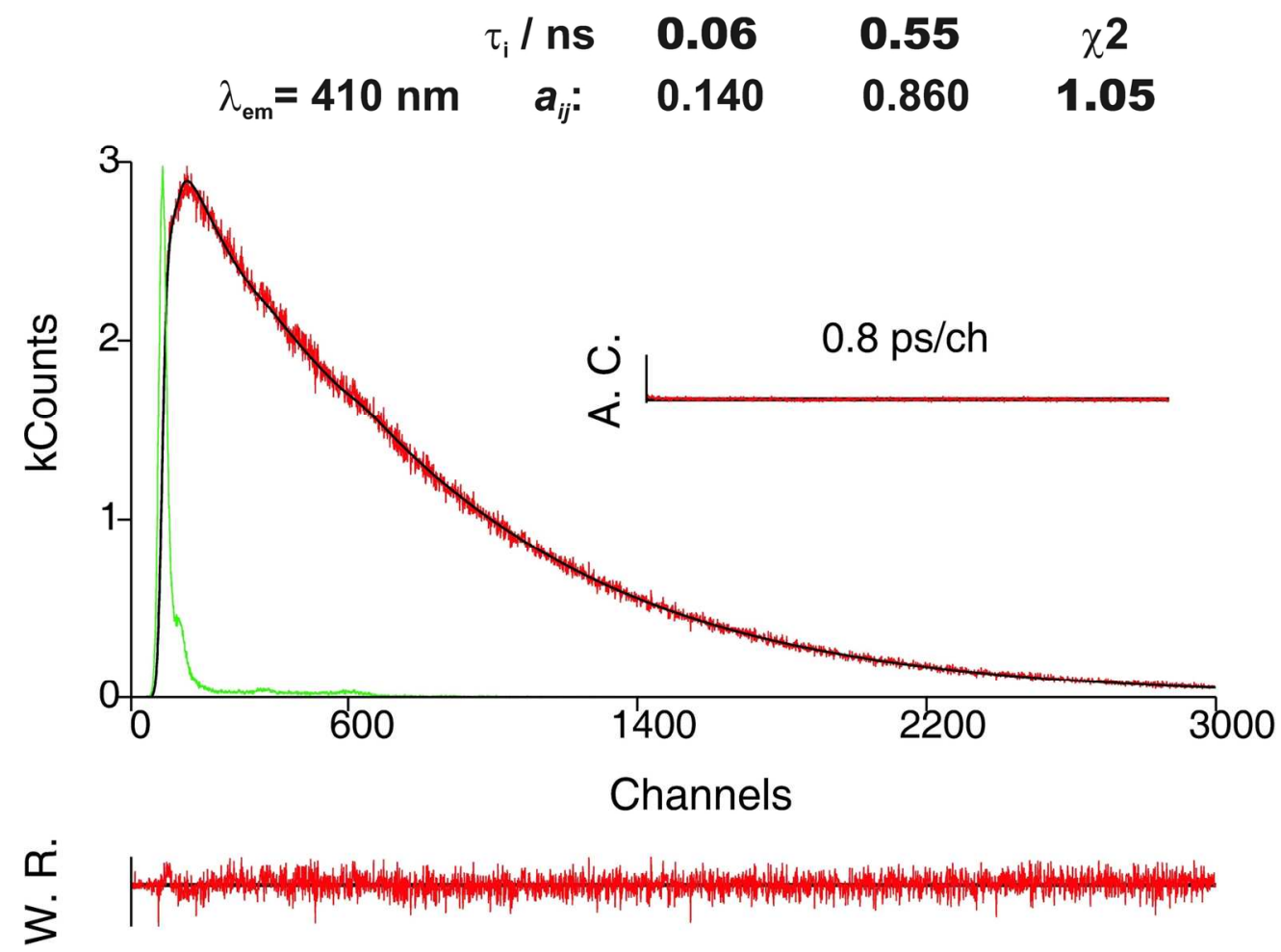

Fluorescence emission decay for PBS-PFP-DPP in dioxane water (1:1) collected at $410 \mathrm{~nm}$ obtained with $\lambda \operatorname{exc} 372 \mathrm{~nm}$ at $298.15 \mathrm{~K}$. The gray lines in the decays are the instrumental response function (IRF). For a better judgment of the quality of the fits, weighted residuals (W.R. scale, $-3 \leq \sigma \leq+3$ ), autocorrelation functions (A.C.) and $\times 2$ are also presented. $150 \times 112 \mathrm{~mm}(300 \times 300 \mathrm{DPI})$ 

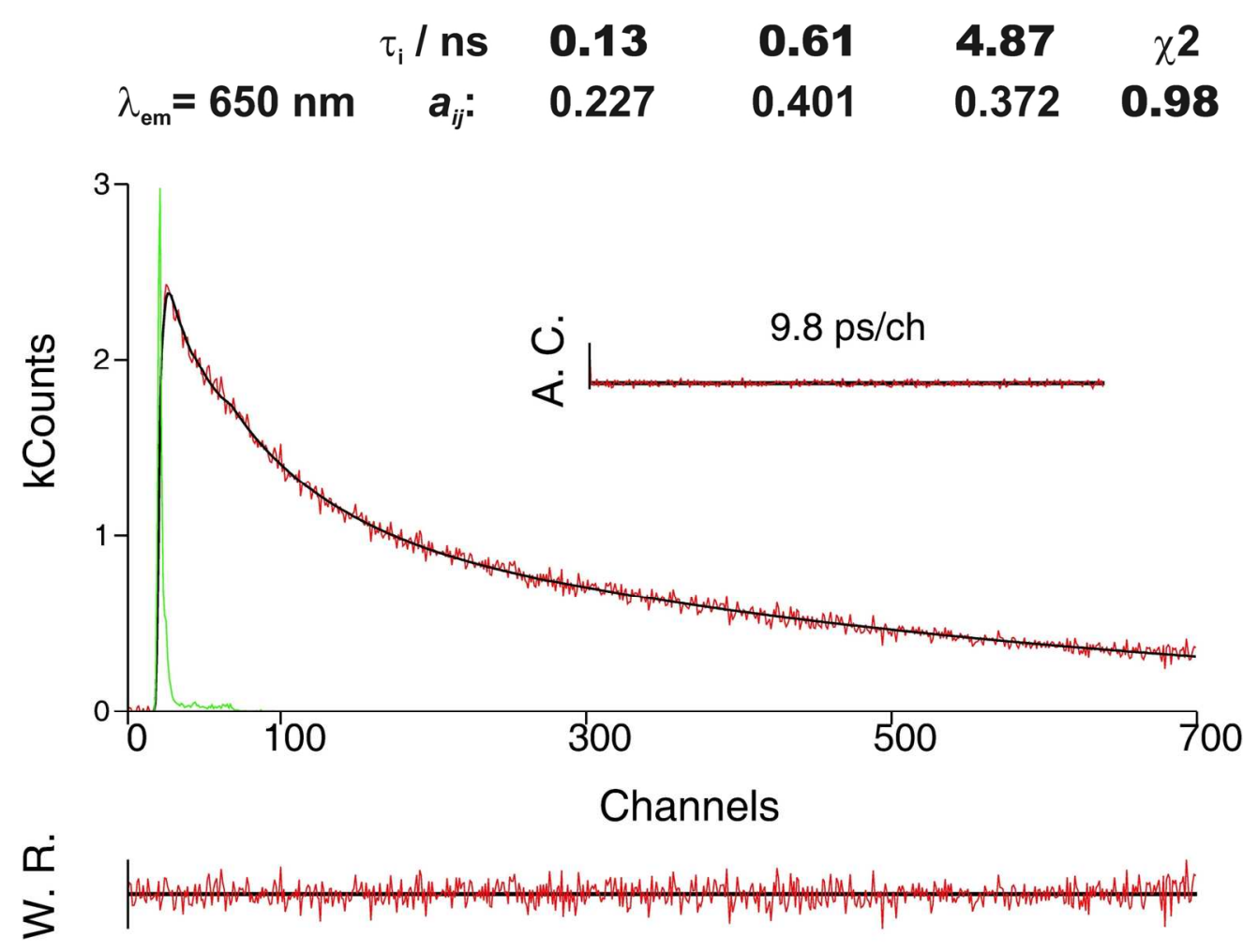

Fluorescence emission decay for PBS-PFP-DPP in dioxane water (1:1) collected at $650 \mathrm{~nm}$ obtained with $\lambda$ exc $372 \mathrm{~nm}$ at $298.15 \mathrm{~K}$. The green lines in the decays are the instrumental response function (IRF). For a better judgment of the quality of the fits, weighted residuals (W.R. scale, $-3 \leq \sigma \leq+3$ ), autocorrelation functions (A.C.) and $\times 2$ are also presented. $151 \times 113 \mathrm{~mm}(300 \times 300 \mathrm{DPI})$ 
henylporphyrinsulfonate, TPPS. 

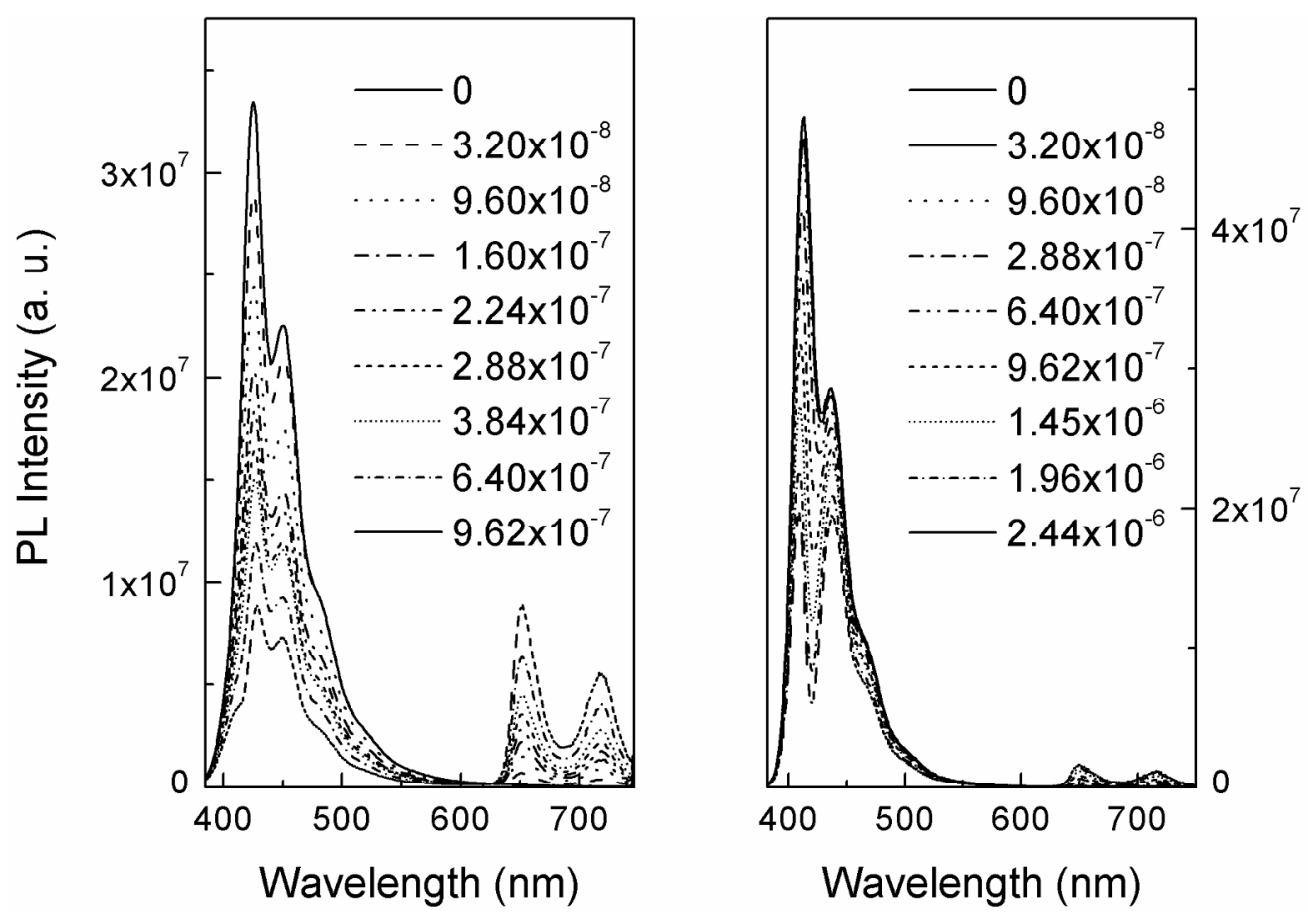

Photoluminescence spectra of PBS-PFP/Ca2+ with increasing TPPS concentrations in water dioxane (1:1) (left) and in $1 \times 10-4 \mathrm{M}$ C12E5 (right). Ca2+ concentration $2 \times 10-3 \mathrm{M}$.

$177 \times 122 \mathrm{~mm}(300 \times 300$ DPI $)$ 

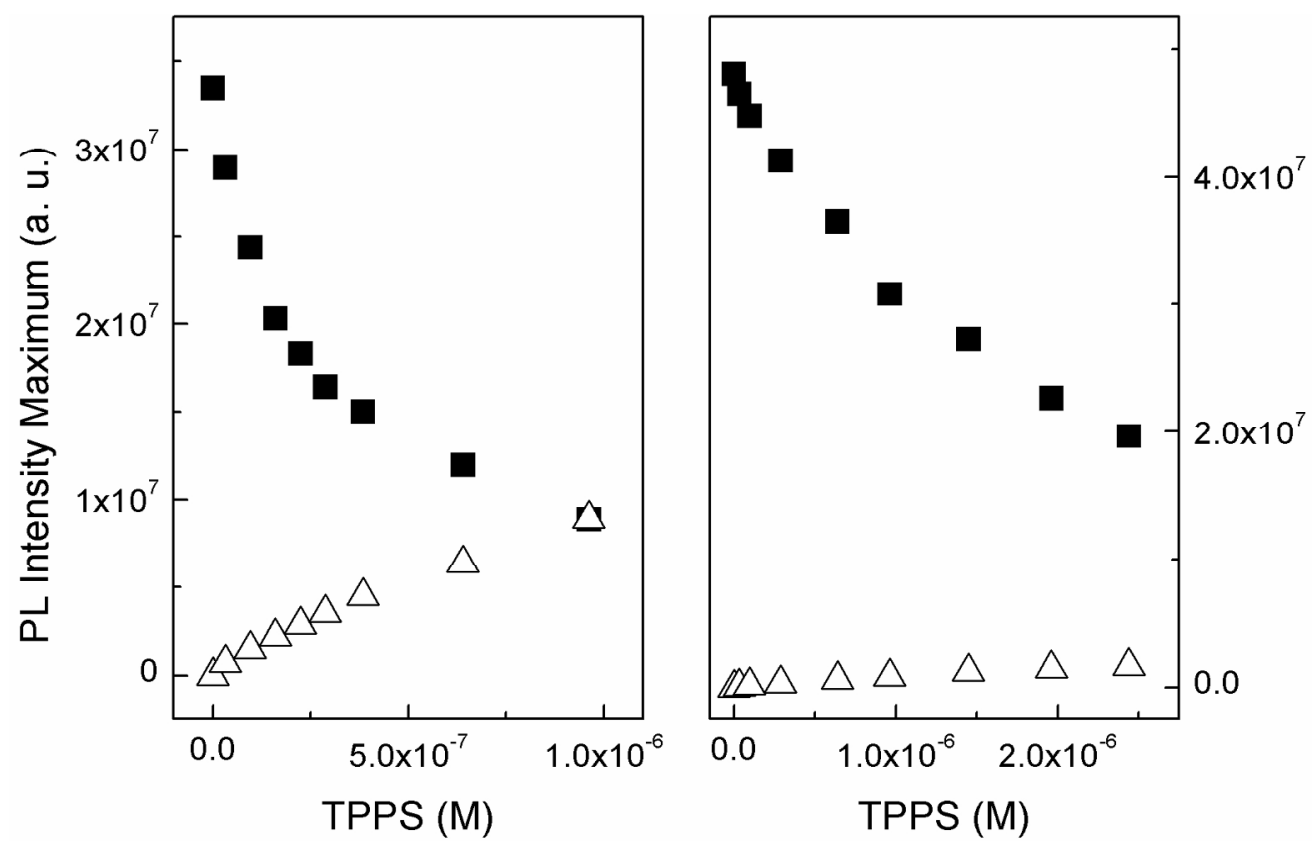

Photoluminescence maximum intensity as a function of TPPS concentration in water dioxane (1:1) (left) and in $1 \times 10-4 M$ C12E5 (right); squares: PBS-PFP emission and triangles: TPPS emission.

$177 \times 112 \mathrm{~mm}(300 \times 300 \mathrm{DPI})$ 

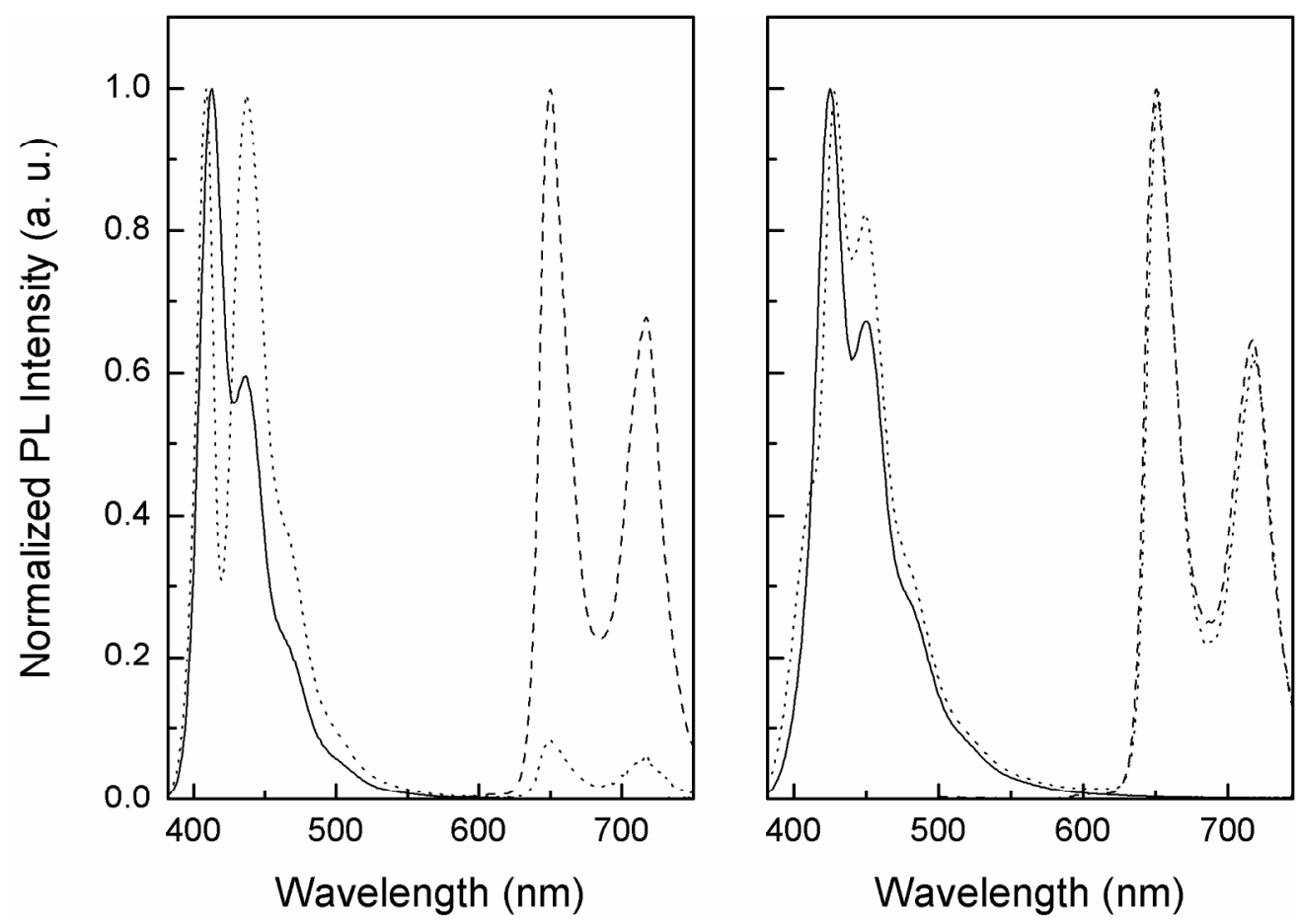

Photoluminescence spectra of PBS-PFP without TPPS (solid line) and with maxima TPPS concentration (dot line), obtained with excitation in the PF absorption maximum and TPPS emission (dash line) obtained with excitation at $420 \mathrm{~nm}$, in water dioxane (1:1) (right) and in 1×10-4M C12E5 (left). $177 \times 125 \mathrm{~mm}(300 \times 300 \mathrm{DPI})$ 

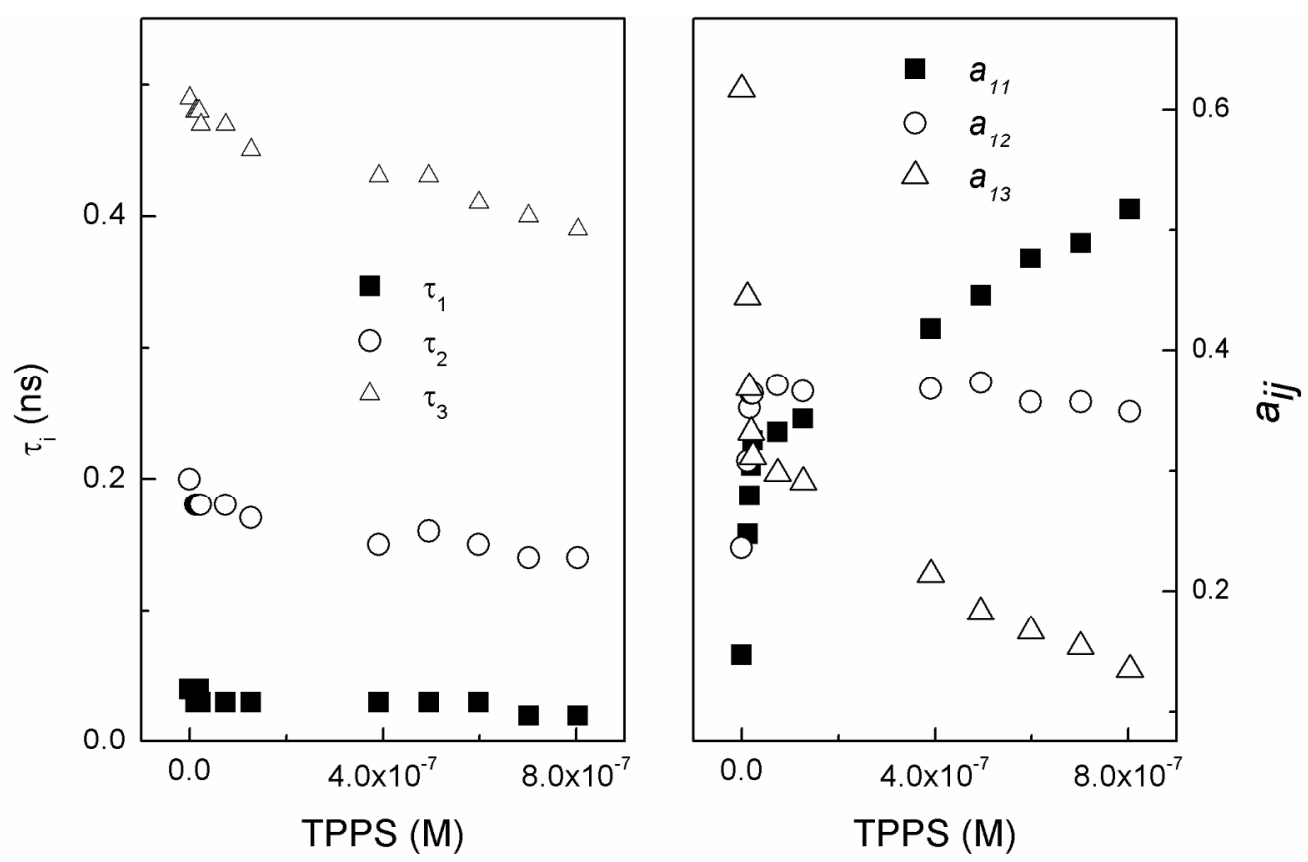

Fluorescence decay times (Ti) and amplitudes (aij) of PBS-PFP (10-6 M) with Ca2+ $(1 \times 10-3 \mathrm{M})$ in $1 \times 10-4 \mathrm{M}$ C12E5 as a function of TPPS concentration. $177 \times 115 \mathrm{~mm}(300 \times 300 \mathrm{DPI})$ 


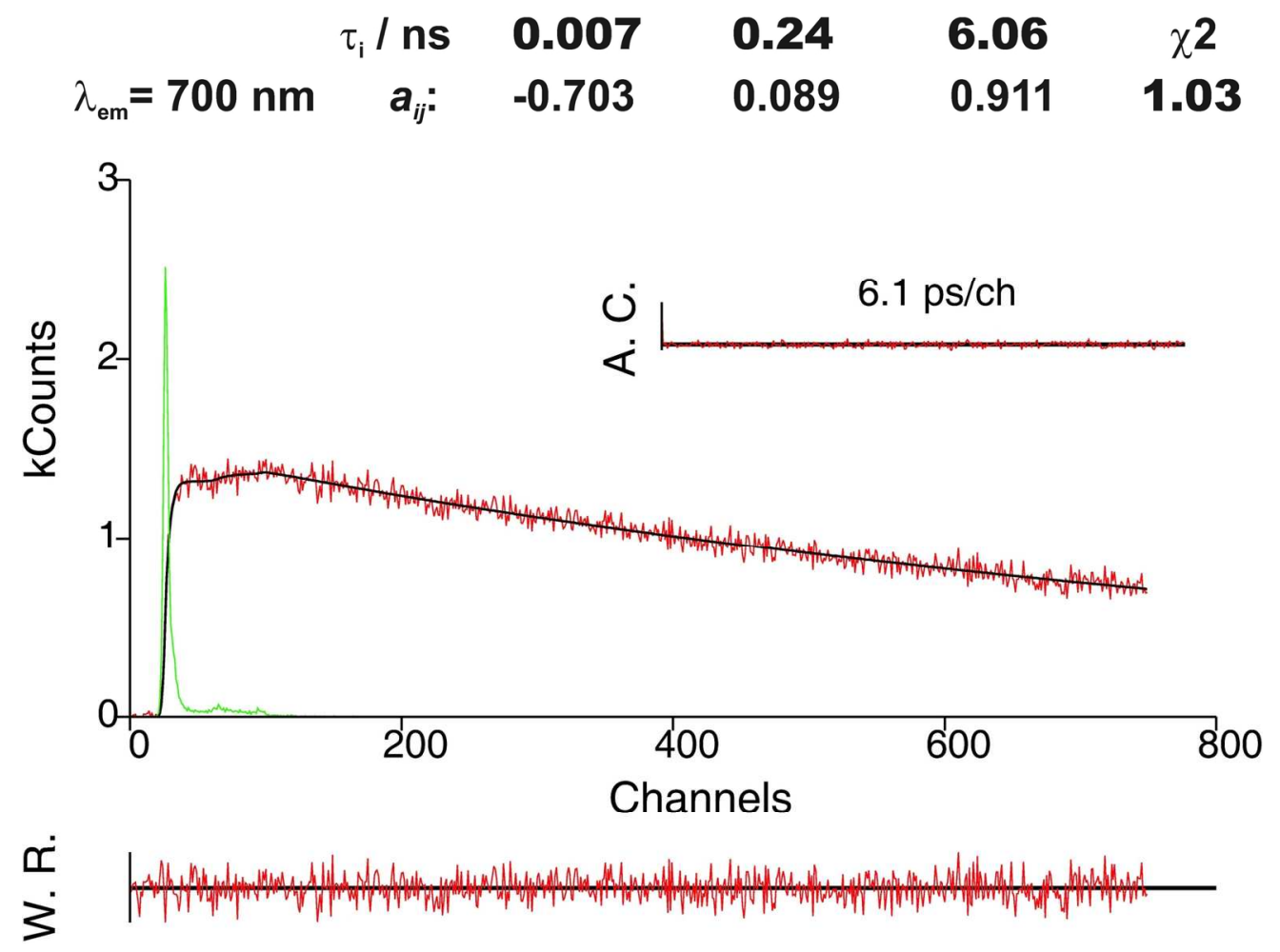

Fluorescence emission decay of PBS-PFP (10-6 M) with Ca2+ $(1 \times 10-3 \mathrm{M})$ in $1 \times 10-4 \mathrm{M}$ C12E5 and TPPS concentration maxima, obtained with $\lambda \operatorname{exc} 392 \mathrm{~nm}$ at $298.15 \mathrm{~K}$. The gray lines in the decays are the instrumental response function (IRF). For a better judgment of the quality of the fits weighted residuals (W.R. scale, $-3 \leq \sigma \leq+3$ ), autocorrelation functions (A.C.) and $X 2$ are also presented. $150 \times 112 \mathrm{~mm}(300 \times 300 \mathrm{DPI})$ 

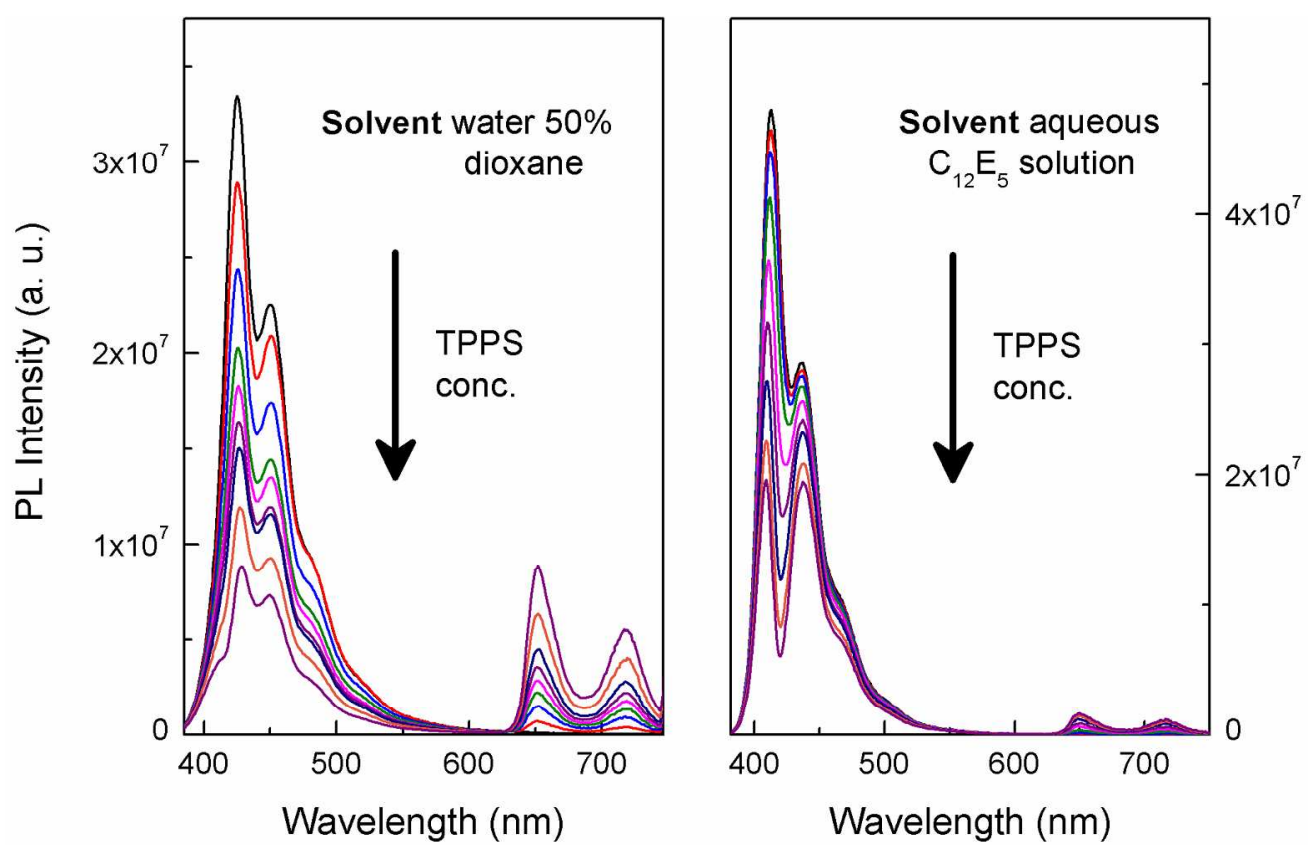

$177 \times 113 \mathrm{~mm}(300 \times 300 \mathrm{DPI})$ 


\section{Energy Transfer from Fluorene Based Conjugated Polyelectrolytes to On- chain and Self-Assembled Porphyrin Units}

Ana T. Marques a,b, Sara M. A. Pinto a, Carlos J. P. Monteiro a, J. Sérgio Seixas de Melo a, Hugh D. Burrows a, Ullrich Scherf b, Mário J. F. Calvete a and Mariette M. Pereira ${ }^{a}$

a Chemistry Department, University of Coimbra, Rua Larga 3004-535, Coimbra, Portugal

${ }^{b}$ Makromolekulare Chemie, Bergische Universität Wuppertal, , D-42097 Wuppertal, Germany

\section{Abstract}

A new water soluble fluorene based polyelectrolyte containing on-chain porphyrin units has been synthesised via Suzuki coupling, for use in optoelectronic devices. The material consist of a random copolymer of poly\{1,4phenylene-[9,9-bis(4-phenoxy butylsulfonate)]fluorene-2,7-diyl\} (PBS-PFP) and a 5,15-diphenylporphyrin (DPP). The porphyrin concentration was kept low (around 10\% molar) to prevent copolymer aggregation and its consequent fluorescent quenching. The energy transfer process between the PBS-PFP units and the porphyrin has been investigated through steady state and time resolved measurements. The copolymer PBS-PFP-DPP displays two different emissions one located in the blue region of the spectra, corresponding to the fluorene part and another in the red, due to fluorescent DPP units either formed directly or by exciton transfer. However, relatively inefficient energy transfer from the PFP to the on-chain porphyrin units was observed. We compare this with a system involving an anionic blue-light-emitting donor PBS-PFP and anionic red-lightemitting energy acceptor meso-tetrakisphenylporphyrinsulfonate (TPPS), selfassembled by electrostatic attraction induced by $\mathrm{Ca}^{2+}$. Based on previous studies related to chain aggregation of the anionic copolymer PBS-PFP, two different solvent media were chosen to further explore the possibilities of the selfassembled system: dioxane-water co-solvent and the non-ionic surfactant ndodecylpentaoxyethylene glycol ether $\left(\mathrm{C}_{12} \mathrm{E}_{5}\right)$. In contrast, with the on-chain PBS-PFP-DPP system, the strong overlap of the 0-0 emission peak of the PBS-PFP 
and the Soret absorption band of the TPPS results in an efficient Förster transfer (FRET). This is strongly dependent upon the solvent medium used.

\section{Introduction}

The development of efficient conjugated polymer materials for organic electronics is a challenging area, with intensive ongoing research in topics such as organic light emitting diodes (OLEDs), organic field effect transistors (OFETs), photovoltaics, sensors and nanowires ${ }^{1-6}$. The addition of different chromophores as functional units to these conjugated polymer (CP) systems allows the introduction of new properties by tuning the emission through electronic energy transfer, and hence, the design of new intelligent materials ${ }^{4-9}$. In OLEDs, fullcolour displays can be achieved by combining blue light-emitting fluorescent materials (either as emitter or as hosts) with green and red fluorescent dopants as the emitters 10-14. Initial studies on such energy transfer systems generally used blends of donor and acceptor. However, this has the limitation that it often leads to phase separation. Greater efficiency may be anticipated if the chromophore is attached to the conjugated polymer, either by covalently bonding in the backbone, or by linking to the side chains. When bonding is in the main chain, the electronic structure, HOMO/LUMO levels and bandgaps of CPs can be manipulated through arrangement of electron or energy donor (D) and acceptor (A) units 15-17. Such covalent attachment of a dye molecule to the polymer backbone, will broaden the absorption window of the conjugated polymer, and extend it to longer wavelengths 18-20. This is of particular importance in polymer bulk heterojunction (BHJ) solar cell devices, since extending the spectral range of the polymeric material to the red region will increase light absorption by the active layer, leading to higher short-circuit currents and efficiencies 18-22. In contrast to these structural and spectral advantages, experimental studies indicate that intra-chain energy transfer in isolated polymer chains is up to an order of magnitude less efficient than energy transfer between chains in polymer films. ${ }^{23}$ Our goal is to develop methods of increasing electronic energy transfer within isolated conjugated polymer chains. 
Poly(para-phenylene) type polymers (PPP) and the related polyfluorenes (PFs) are a particularly interesting class of conjugated polymers. PFs display high photoluminescence efficiencies and quantum yield, both in solution and in solid state, with emission wavelengths in the blue spectral region, in addition to good thermal and photostablility 24, 25. Fluorene based copolymers are also attractive as energy donors in Förster resonance energy transfer 26, 27 (FRET). By doping, or covalent attachment of a lower bandgap material in the PF main chain, the polymer emission can be tuned to longer wavelengths by FRET 28. For red emission, either polar moieties, such as electron donor substituted pyran derivatives, or non polar ones involving extensive $\pi$ conjugation, such as perylene derivatives or porphyrin-type macrocyclic compounds have been studied 29,30 . Systems involving PFs and red emitting porphyrins are particularly good candidates for FRET because of the excellent spectral overlap of donor emission and acceptor absorption as is the case of systems involving PFs and porphyrins ${ }^{30-35}$. Porphyrins are compounds of interest because their valuable photophysical properties 36 allow their use in a large number of practical applications, such as molecular photonic devices, artificial photosynthetic systems and dye-sensitized solar cells 4, 18, 37-39. Also, porphyrins bearing hydrophilic pendant groups are able to interact with relevant biomolecules, as nucleic acids, polypeptides and proteins 40 . In addition, these are excellent systems for testing models of electronic energy transfer in conjugated polymers 41 - 44. In particular, the Förster model for electronic energy transfer using point dipoles appears to break down at small PF-porphyrin distances, and the efficiency of energy transfer is suggested to show considerable differences if the two moieties are colinear or cofacial ${ }^{43}$. In this paper we compare singlet-singlet electronic energy transfer in two fluorene based anionic conjugated polyelectrolytes which have different PF-porphyrin orientations. For the colinear system, we synthesized an anionic poly(fluorene-alt-phenylene) with porphyrin units incorporated randomly on the backbone (Scheme 1). In the second system, we have self-assembled the polymer and porphyrin. We have previously shown electronic energy transfer within a self-assembled system involving anionic porphyrins and cationic fluorene based conjugated polyelectrolytes ${ }^{32}$. Metal ions, such as calcium(II), can also induce self-assembly of anionic conjugated 
polyelectrolytes 45,46 . We extend this to calcium(II) induced self-assembly of an anionic poly(fluorene-alt-phenylene) conjugated polyelectrolyte and an anionic tetraphenylporphyrin, and have studied the electronic energy transfer both in large aggregates and surfactant modulated systems as models for cofacial energy transfer. 


\section{Experimental Section}

Synthesis 2,7-dibromo-9,9-bis(4-sulfonylbutoxyphenyl)fluorene and poly\{1,4phenylene-[9,9-bis(4-phenoxy butylsulfonate)]fluorene-2,7-diyl $\quad$ (PBS-PFP) were prepared according to published procedures and have been described elsewhere ${ }^{41}$. The synthesis of dipyrromethane and 5,15-diphenylporphyrin was carried out with slight modifications of previously described methods ${ }^{47,48}$ see SI for the compounds characterization.

5,15-Dibromo-10,20-diphenylporphyrin, DPP. $300 \mathrm{mg}$ of 5,15diphenylporphyrin $(0.58 \mathrm{mmol})$ were dissolved in $300 \mathrm{~mL} \mathrm{CHCl}_{3}$ and $2.4 \mathrm{~mL}$ of pyridine. The mixture was cooled to $0^{\circ} \mathrm{C}$ and $240 \mathrm{mg}$ of $\mathrm{N}$-bromosuccinimide (1.22 mmol, $2.1 \mathrm{eq}$ ) were added and the solution was stirred for $60 \mathrm{~min}$. The reaction was quenched with acetone $(50 \mathrm{~mL})$ and the solvent was evaporated yielding a product that was washed with methanol ${ }^{48}$. Recrystallization from toluene/MeOH gave $347 \mathrm{mg}$ of the title compound as purple crystals $(0.56 \mathrm{mmol}$, 96\%) ${ }^{1} \mathrm{H} \mathrm{NMR}\left(400 \mathrm{MHz}, \mathrm{CDCl}_{3}\right) 9.62\left(\mathrm{~d}, J=4.7 \mathrm{~Hz}, 4 \mathrm{H}, \mathrm{H}_{\beta}\right), 8.84(\mathrm{~d}, J=4.7 \mathrm{~Hz}, 4 \mathrm{H}$, $\mathrm{H}_{\beta}$ ), 8.17-8.15 (m, 4H, Ph-Ho), 7.83-7.75 (m, 6H, Ph-Hm,p), -2.72 (br s, 2H, NH).

The HOMO values of the DPP were measured using atmospheric pressure photoelectron spectrometry (Riken Keiki $A C$-2) and the LUMO calculated from the HOMO and optical band-gap (determined via the intersection of the absorption and emission thin film spectra) ${ }^{49-51}$. HOMO $=5.04 \mathrm{eV}$ and LUMO $=$ $3.17 \mathrm{eV}$.

Poly\{1,4-phenylene $\}-c o-\{[9,9-b i s(4-p h e n o x y \quad$ butylsulfonate) $]$ fluorene-2,7diyl\}-alt-\{1,4-phenylene(5,15-diphenylporphyrin) PBS-PFP-DPP. For the preparation of the copolymer PBS-PFP-DPP, a mixture of 2,7-dibromo-9,9-bis(4sulfonylbutoxyphenyl)fluorene (0.742 g, $0.90 \mathrm{mmol})$, 5,15-dibromo-10,20diphenylporphyrin, DPP (0.062 g, $0.10 \mathrm{mmol})$, 1,4-benzenediboronic acid (0.166 g, $1 \mathrm{mmol}), \mathrm{Pd}\left(\mathrm{PPh}_{3}\right)_{4}(50 \mathrm{mg})$ and $\mathrm{Na}_{2} \mathrm{CO}_{3}(1.0 \mathrm{~g}, 9.4 \mathrm{mmol}){ }^{41}$ in $40 \mathrm{~mL}$ of THF and $20 \mathrm{~mL}$ water, were reacted for 4 days at $110{ }^{\circ} \mathrm{C}$. The aqueous layer was washed with chloroform and concentrated to dryness. The residue was extracted with dichloromethane via Soxhlet, redissolved in a mixture of water and THF $50 \%(\mathrm{v} / \mathrm{v})$ and purified by dialysis using a membrane with a cut-off of 3500 g.mol-1. Based on the monomer/DPP ratio in the starting reaction mixture, the 
copolymer is expected to contain on average 10\% (mole percent) DPP units. Total yield of the copolymer PBS-PFP-DPP was 655mg (91\%). ${ }^{1} \mathrm{NMR}$ (600 MHz, d-THF 50\% $\mathrm{D}_{2} \mathrm{O}$, ppm) 8.95-8.87 (ar-H DPP), 8.2 - 6.6 (ar-H DPP and ar-H fluorene), 4.1-3.9 $\left(\gamma-\mathrm{CH}_{2}\right), 2.98-2.86\left(\alpha-\mathrm{CH}_{2}\right), 2.0-1.9\left(\beta, \delta-\mathrm{CH}_{2}\right)$.

GPC (NMP, LiBr, UV-detection) $\mathrm{M}_{\mathrm{w}}=1400$ g.mol-1, $\mathrm{M}_{\mathrm{w}} / \mathrm{M}_{\mathrm{n}}=1.4$. The $\mathrm{M}_{\mathrm{w}}$ of the copolymer are likely to be considerably underestimated due to the interactions between the polyelectrolytes and the column material.

Steady State Spectroscopic Measurements. The measurements were recorded in water, and dioxane - water (1:1). All the solvents were of spectroscopic grade and Milli-Q water was used. To ensure almost complete dissolution of the copolymer, solutions were stirred overnight. Non-ionic surfactant ndodecylpentaoxyethylene glycol ether $\left(\mathrm{C}_{12} \mathrm{E}_{5}\right)$ was purchased from Aldrich and used without further purification. Absorption spectra were recorded using a Shimadzu UV-2100 spectrophotometer with a minimum resolution of $0.2 \mathrm{~nm}$. For the steady-state measurements, fluorescence spectra were recorded with a Horiba-Jobin-Ivon SPEX Fluorog 3-22 spectrometer and were corrected for the instrumental response of the system. Fluorescence quantum yields were measured using quinine sulfate in $0.5 \mathrm{M}$ sulfuric acid (for the poly(fluorene-altphenylene) region) and meso-tetrakis-phenylporphyrin (TPP) in toluene (for the DPP region) as references. Corrections were made for changes in refractive index 52.

Picosecond TCSPC Experiments. Picosecond time-resolved fluorescence measurements were performed using a home-built picosecond TCSPC apparatus, in which the excitation source consists of a picosecond Spectra Physics modelock Tsunami laser (Ti : sapphire) model 3950 (repetition rate of about $82 \mathrm{MHz}$, tuning range 700-1000 nm), pumped by a Millennia Pro-10s, frequency-doubled continuous wave $(\mathrm{CW})$, diode-pumped, solid-state laser $\left(\lambda_{\mathrm{em}}=532 \mathrm{~nm}\right)$. A harmonic generator model GWU-23PS (Spectra-Physics) is used to produce the second and third harmonic from the $\mathrm{Ti}$ : sapphire laser exciting beam frequency 
output. The samples were measured with excitation at $372 \mathrm{~nm}$ and the horizontally polarized output beam from the GWU (second harmonic) was first passed through a ThorLabs depolarizer (WDPOL-A) and after by a GlanThompson polarizer (Newport 10GT04) with vertical polarization. Emission at $90^{\circ}$ geometry collected at magic angle polarization was detected through a double subtractive Oriel Cornerstone 260 monochromator by a Hamamatsu microchannel plate photomultiplier (R3809U-50). Signal acquisition and data processing was performed employing a Becker \& Hickl SPC-630 TCSPC module. Fluorescence decays and the instrumental response function (IRF) where collected using 4096 channels in a 0.814, 6.1 and 9.8 ps/channel scale, until $1.5 \times$ $10^{3}$ and $3 \times 10^{3}$ counts at maximum were reached. The full width at halfmaximum (fwhw) of the IRF was about 22 ps and was highly reproducible with identical system parameters. A more detailed description of this equipment can be found in ref. 53 . 


\section{Results and Discussion}

\section{Absorption and Fluorescence}

The anionic copolymer poly(fluorene-alt-phenylene)-porphyrin (PBS-PFP-DPP) (Scheme 1) was studied by UV-Vis absorption, photoluminescence (PL) spectroscopy and time-resolved fluorescence (TS-SPC) measurements. Anionic fluorene based conjugated polyelectrolytes tend to aggregate in aqueous solution to form ill defined clusters. ${ }^{54}$ To minimize this, measurements have been made in a 1:1 dioxane-water mixture and in water in the presence of $1 \times 10^{-4} \mathrm{M}$ nonionic surfactant $\mathrm{C}_{12} \mathrm{E}_{5}$.

Scheme 1. Chemical structures of the homopolymer PBS-PFP, the DPP monomer and the copolymer PBS-PFP-DPP.

In both solvent systems two characteristic absorption regions are observed in the UV-Vis absorption spectrum, which are attributed to the poly(fluorene-altphenylene) backbone (broad absorption at $365 \mathrm{~nm}$ ) and to the on-chain porphyrin (DPP) units (various bands between 420 and $650 \mathrm{~nm}$ ) - Table 1, Figures 1 and 2 . The strong narrow absorption peak at $420 \mathrm{~nm}$ and the four smaller absorption peaks between 520 and $650 \mathrm{~nm}$ correspond to the so-called "Soret" and "Q" bands, respectively, typical of porphyrins. 55 The presence of four absorptions in the $\mathrm{Q}$ band region, corresponding to the $(0,0)$ and $(0,1)$ vibronics of the Qx and Qy bands, confirms that the porphyrin is present as its free base. Excitation of PBS-PFP-DPP at $365 \mathrm{~nm}$ leads to emission from both PF and DPP, while excitation at $420 \mathrm{~nm}$ shows only emission from the DPP units (Figures 1 and 2). Fluorescence excitation spectra for emission in the porphyrin region reveals two maxima in the PF and DPP region, demonstrating efficient electronic energy transfer from the fluorene to the porphyrin units. However, differences in the relative intensities are observed in dioxane-water and in $1 \times 10^{-4} \mathrm{M}$ aqueous $\mathrm{C}_{12} \mathrm{E}_{5}$ solutions. In particular, the ratio of PF to DPP intensities is higher in $\mathrm{C}_{12} \mathrm{E}_{5}$ solution than in dioxane-water. Small angle X-ray scattering (SAXS), cryotransmission electron microscopy, molecular dynamics simulations, 56 
together with small angle neutron (SANS) scattering on PBS-PFP solutions in the presence of $\mathrm{C}_{12} \mathrm{E}_{5}{ }^{57}$, strongly suggest that in the presence of $\mathrm{C}_{12} \mathrm{E}_{5}$, the conjugated polymer is present as a mixed cylindrical aggregate in which the polymer backbone is surrounded by a layer of surfactant molecules. Furthermore, a similar effect was observed with the closely related poly\{9,9bis[6-(N,N,N-trimethylammonium)alkyl]fluorene-co-1,4-phenylene $\}$ iodide cationic conjugated polyelectrolyte ${ }^{58}$. This is expected to have the two effects of increasing backbone rigidity and at the same time decreasing solvent access to the PF chain. We believe that with PBS-PFP-DPP, the increased rigidity will facilitate on-chain exciton migration and, hence, the efficiency of energy transfer to the porphyrin unit.

Quantum efficiency (PLQY) measurements made for the PBS-PFP-DPP copolymer in the solvent mixture dioxane-water (1:1) and in an aqueous solution of non-ionic surfactant $\mathrm{C}_{12} \mathrm{E}_{5}$ are presented in Table 1. The energy transfer quantum yields for PFP to DP units in greater in $\mathrm{C}_{12} \mathrm{E}_{5}$ solution than in $1 / 1$ dioxane water. This may be associated with decrease in conformational disorder when encapsulated by the surfactant and is consistent with the results from the fluorene excitation spectra. There is a slight decrease in the PLQY values for the copolymer PBS-PFP-DPP compared with that of the polymer without the porphyrin chromophore, PBS-PFP, for the same solvents, 0.52 in water dioxane $(1: 1)$ and 0.4559 in $\mathrm{C}_{12} \mathrm{E}_{5}$. In part, this may result from photogenerated excitons being transferred to the DPP units. However, the sum of PLQY for emission from PF and DPP units is, in both cases, less than with PBSPFP in the two solvents, indicating that some loss mechanism is also involved.

As shown in Figure 3, there is a strong overlap between the 0-0 emission band of the homopolymer PBS-PFP and the Soret absorption of the DPP; since the emission from the Soret band is weak, it acts as a dark state and the emission arises preferentially from the lowest energy $Q_{x}$ band ${ }^{35}$.

Table 1. Photophysical parameters of PBS-PFP-DPP in dioxane-water (1:1) and $1 \times 10^{-4} \mathrm{M} \mathrm{C}_{12} \mathrm{E}_{5}$. 
Figure 1. a) Absorption (solid line) and emission spectra (dashed line) of PBSPFP-DPP in dioxane-water (1:1), with excitation at $365 \mathrm{~nm}$ (dashed line) and 420 $\mathrm{nm}$ (dotted line). The inset depicts the $600-750 \mathrm{~nm}$ region of the PBS-PFP-DPP emission shown in the main plot. b) Fluorescence excitation spectra with emission at $410 \mathrm{~nm}$ (solid line) and emission at $655 \mathrm{~nm}$ (dashed line) of PBSPFP-DPP in dioxane-water (1:1).

Figure 2. a) Absorption (solid line) and emission spectra (dashed line) of PBSPFP-DPP in $1 \times 10^{-4} \mathrm{M}$ aqueous $\mathrm{C}_{12} \mathrm{E}_{5}$ solution, with excitation at $365 \mathrm{~nm}$ (solid line) and $420 \mathrm{~nm}$ (dotted line). b) Fluorescence excitation spectra with emission at $410 \mathrm{~nm}$ (solid line) and emission at $655 \mathrm{~nm}$ (dashed line) of PBS-PFP-DPP in $1 \times 10^{-4} \mathrm{M}$ aqueous $\mathrm{C}_{12} \mathrm{E}_{5}$.

Figure 3. Spectral overlap between the donor PBS-PFP (dotted line) and the acceptor DPP (full line).

\section{Time-resolved fluorescence}

Fluorescence decays were obtained in the dioxane-water (1:1) mixture upon excitation in the poly(fluorene-alt-phenylene) unit (372 nm) and collecting at the PF and DPP emission maximum (Figure 4 and Table 2). A value of 550 ps ( $\left.\tau_{3}\right)$ that dominates the decay, together with a shorter lifetime value of 60 ps $\left(\tau_{1}\right)$ is found when the data is collected at $410 \mathrm{~nm}$ in agreement with previous observations ${ }^{60}$. The longer decay lifetime $\left(\tau_{3}\right)$ has a value very close to the previously described for PBS-PFP dispersed in the $\mathrm{C}_{12} \mathrm{E}_{5}$ micellar system ${ }^{41,61}$ and is attributed to the natural decay of the PF backbone ${ }^{41}$. The fast component $\left(\tau_{1}\right)$ is suggested to be related either to the formation of an initially formed nonrelaxed conformer that decays giving rise to a more stable one ${ }^{60}$, or to on-chain energy transfer process ${ }^{60}$. Nevertheless, sums of three discrete exponentials functions were needed to fit the excited state data collected at $650 \mathrm{~nm}$. In 
dioxane-water, an intermediate decay component of 130 ps is observed. A similar decay time of approximately 130 ps has been reported previously for the cluster morphology adopted by polyelectrolytes in solution 62 . However, this seems unlikely in the present case, and, in agreement with suggestions of a closely related self assembled porphyrin/conjugated polyelectrolyte system we feel that this component is more likely due to exciton migration along the polymer chain ${ }^{32}$. This component becomes longer lived and more important in $\mathrm{C}_{12} \mathrm{E}_{5}$ solutions, the system showing more efficient energy migration from PF to DPP units. The 4.87 ns component is assigned to emission from the DPP units, in agreement with the values published for PPV and PF doped with porphyrins ${ }^{34}$, 63.

Table 2. Fluorescence decay times $\left(\tau_{\mathrm{i}}\right)$ and pre-exponential factors $\left(\mathrm{a}_{\mathrm{ij}}\right)$ for the copolymer PBS-PFP-DPP, obtained with excitation at $372 \mathrm{~nm}$, emission $\left(\lambda_{\mathrm{em}}\right)$ at the wavelength maxima and $\mathrm{T}=298 \mathrm{~K}$.

Figure 4. Fluorescence emission decay for PBS-PFP-DPP in dioxane water (1:1) collected at a) $410 \mathrm{~nm}$ and b) $650 \mathrm{~nm}$ obtained with $\lambda_{\text {exc }} 372 \mathrm{~nm}$ at $298.15 \mathrm{~K}$. The gray lines in the decays are the instrumental response function (IRF). For a better judgment of the quality of the fits, weighted residuals (W.R. scale, $-3 \leq \sigma \leq$ +3 ), autocorrelation functions (A.C.) and $\chi^{2}$ are also presented.

TPPS self-assembled with PBS-PFP via calcium (II) binding

With PBS-PFP-DPP, the porphyrin is expected to be collinear with the PF units. We will now discuss the second PF-porphyrin energy transfer system in which the anionic porphyrin TPPS is self-assembled by calcium(II) ions to the homopolymer PBS-PFP (Scheme 2), and the PF and porphyrin units are expected to be cofacial. The potential application of this system in sensing and in molecular logic will be described elsewhere. ${ }^{64}$ We have previously reported the 
photophysics of a cationic PFP system self assembled by electrostatic interactions to TPPS. ${ }^{32}$ These self-assembled systems have the advantage that by tuning the solvent and stoichiometry, it is possible to control the amount of porphyrin and, possibly, structural morphology and disorder of the materials. The characterization of the hydrophilic porphyrin has been described elsewhere. 65 The absorption and emission spectra of PBS-PFP were recorded in the same solvents used with PBS-PFP-DPP, dioxane-water (1:1) and $1 \times 10^{-4} \mathrm{M}$ aqueous $\mathrm{C}_{12} \mathrm{E}_{5}$ solutions (above the surfactant critical micelle concentration, $\mathrm{cmc}$ ).

Scheme 2. Structure of the electronic energy acceptor mesotetrakisphenylporphyrinsulfonate, TPPS.

Calcium (II) modulates the self-assembly between the two negatively charged components. Energy transfer from the PBS-PFP to the anionic porphyrin is evident from the PL spectra (Figure 5). By adding different concentrations of porphyrin to the polyelectrolyte at fixed $\mathrm{Ca}^{2+}$ concentration $2 \times 10^{-3} \mathrm{M}$ there was a decrease in the fluorescence band in the PF region and a corresponding increase seen in the emission band of the porphyrin $\left(\lambda_{\max }=650 \mathrm{~nm}\right)$. The quenching effect is most pronounced when the polyelectrolyte is dissolved in the dioxanewater co-solvent solution mixture, see Figure 6. As will be seen, significant differences are seen in energy transfer from PF to porphyrin units in the onchain and self-assembled systems, in agreement with the predictions of Wong et al. ${ }^{42}$ In addition to effects of orientation of the donor-acceptor units, other nonradiative deactivation processes may be possible in the PBS-PFP-DPP copolymer, including charge transfer, triplet formation, exciton - exciton annihilation and molecular excimer formation 35, 66, 67. With the low light intensity and dilute solutions used, the latter two processes are unlikely.

For the self-assembled system, control experiments of the effect of $2 \times 10^{-3} \mathrm{M} \mathrm{Ca}^{2+}$ on the photoluminescence of the PBS-PFP copolymer solutions were also performed and no significant differences were observed in the spectral shape or 
maximum (see SI). Nevertheless, the PLQY decreases in the presence of $\mathrm{Ca}^{2+}$ as a consequence of the metal interaction with the polar copolymer side chains inducing aggregation. 46 The photoluminescence deactivation by $\mathrm{Ca}^{2+}$ of the copolymer in the 1:1 dioxane-water mixture is $30 \%$ more effective than in the surfactant solution (see SI). The spectral changes observed in the PL spectra (Figure 7) are mainly due to the strong attenuation by the overlap of the absorption of the porphyrin Soret band and the PBS-PFP copolymer fluorescence (Figure 3) ${ }^{32}$. The PL quenching is more pronounced in dioxane-water (1:1) mixture, Figure 5 and Table 3, since calcium ion induces strong copolymeraggregation ${ }^{46}$, and the large aggregates are likely to favour energy transfer from multiple PBS-PFP units towards TPPS. In contrast, for the self-assembled system in the presence of the non-ionic surfactant, a lower PLQY was found for the TPPS on excitation of PBS-PFP (Table 3). It is known that $\mathrm{C}_{12} \mathrm{E}_{5}$ wraps around the copolymer forming supramolecular structures that shield the PBS-PFP from the aqueous solvent. 55, 68 This means that calcium ions are likely to only bind to the exposed sulfonate groups on a single PBS-PFP chain, such that energy transfer is from one CPE molecule to the bound porphyrin. Small angle X-ray (SAXS) and neutron (SANS) scattering studies are in progress to obtain more structural information on these systems.

Figure 5. Photoluminescence spectra of PBS-PFP/Ca ${ }^{2+}$ with increasing TPPS concentrations in water dioxane (1:1) (left) and in $1 \times 10^{-4} \mathrm{M} \mathrm{C}_{12} \mathrm{E}_{5}$ (right). $\mathrm{Ca}^{2+}$ concentration $2 \times 10^{-3} \mathrm{M}$.

Figure 6. Photoluminescence maximum intensity as a function of TPPS concentration in water dioxane (1:1) (left) and in $1 \times 10^{-4} \mathrm{M} \mathrm{C}_{12} \mathrm{E}_{5}$ (right); squares: PBS-PFP emission and triangles: TPPS emission.

Figure 7. Photoluminescence spectra of PBS-PFP without TPPS (solid line) and with maxima TPPS concentration (dot line), obtained with excitation in the PF 
absorption maximum and TPPS emission (dash line) obtained with excitation at $420 \mathrm{~nm}$, in water dioxane (1:1) (right) and in $1 \times 10^{-4} \mathrm{M} \mathrm{C}_{12} \mathrm{E}_{5}$ (left).

Table 3. Photoluminescence quantum yields of PBS-PFP/Ca ${ }^{2+}$ self assembled with TPPS in dioxane water $(1: 1)$ and $1 \times 10^{-4} \mathrm{M} \mathrm{C}_{12} \mathrm{E}_{5}\left(\mathrm{Ca}^{2+}\right.$ concentration $2 \times 10^{-3}$ M).

Fluorescence decays of the system PBS-PFP+Ca ${ }^{2+}+\mathrm{TPPS}$, with increasing anionic porphyrin concentration were collected at the PBS-PFP. The decays were fitted with sums of three discrete exponential functions and the corresponding decay times and amplitudes, as a function of the porphyrin concentration, are plotted, Figure 8.

Figure 8. Fluorescence decay times $\left(\tau_{\mathrm{i}}\right)$ and amplitudes $\left(a_{i j}\right)$ of PBS-PFP $\left(10^{-6} \mathrm{M}\right)$ with $\mathrm{Ca}^{2+}\left(1 \times 10^{-3} \mathrm{M}\right)$ in $1 \times 10^{-4} \mathrm{M} \mathrm{C}_{12} \mathrm{E}_{5}$ as a function of TPPS concentration.

Figure 9. Fluorescence emission decay of PBS-PFP $\left(10^{-6} \mathrm{M}\right)$ with $\mathrm{Ca}^{2+}\left(1 \times 10^{-3} \mathrm{M}\right)$ in $1 \times 10^{-4} \mathrm{M} \mathrm{C}_{12} \mathrm{E}_{5}$ and TPPS concentration maxima, obtained with $\lambda_{\text {exc }} 392 \mathrm{~nm}$ at 298.15 K. The gray lines in the decays are the instrumental response function (IRF). For a better judgment of the quality of the fits weighted residuals (W.R. scale, $-3 \leq \sigma \leq+3$ ), autocorrelation functions (A.C.) and $\chi^{2}$ are also presented.

The dependence of the decay times and amplitudes, presented in Figure 8 is similar to the behaviour observed for the system involving the cationic fluorene based polyelectrolyte HTMA-PFP and different hydrophilic porphyrins ${ }^{32}$. The long component $\left(\tau_{3}\right)$ has a value very close to that previously reported for PBSPFP with $\mathrm{C}_{12} \mathrm{E}_{5}$ in water ${ }^{41}$ and the presence of calcium does not seem to affect the lifetime of the polyelectrolyte, see SI. The PBS-PFP lifetime is, as previously observed in the PL data, quenched with increasing porphyrin concentration 
(Figure 6). Attribution of the fastest component ( $\tau_{1}$ ca. 20 ps for a TPPS concentration of $8.03 \times 10^{-7} \mathrm{M}$ ) is still troublesome and it has been attributed to both energy transfer and conformational relaxation of the copolymer chain ${ }^{32,60}$. However, with the present system and based on the decay profile and data of Figure 9, a rise time (ca. 7 ps at the same TPPS concentration) is attributed to the fast component, providing evidence that energy transfer is taking place and dominating the deactivation pathways occurring in the excited states of the selfassembled donor/acceptor system. The origin of the intermediate lifetime component, $\tau_{2}$, has been discussed previously and attributed to exciton migration, either on-chain or intra-chain (within aggregates) $32,62$.

The PL efficiency of the self-assembled system is always greater than with the copolymer PBS-PFP-DPP. This resembles the behaviour described for MEH-PPV porphyrin blends ${ }^{69}$. As demonstrated by Morgado et al. the distribution of the porphyrin chromophore within the polymer does not match the one for the selfassembled system and the copolymer. Hence, the differences in the efficiency of the energy transfer and the concentration quenching effects might contribute for the different observations. The results are also in complete agreement with the ideas of Wong et al. on cofacial energy transfer in PF-porphyrin systems being more efficient than the collinear case. ${ }^{42}$ Whilst the porphyrin ring and polymer backbone may not be perfectly parallel, a small deviation from cofacial geometry is not likely to significantly affect the efficiency of Förster energy transfer. Although these authors have questioned the validity of the use of point dipoles in Förster theory 70,71 to treat electronic energy transfer between these donor and an acceptor units, it is instructive to compute the radius, $\mathrm{R}_{0}$ that identify the distance at which the transfer occurs with 50\% efficiency. Table 4 comprise the $\mathrm{R}_{0}$ values for the PBS-PFP-DPP copolymer and for the self-assembled system PBS-PFP/TPPS.

Table 4. Föster radius, $\mathrm{R}_{0}$, of PBS-PFP-DPP and of PBS-PFP with TPPS. 
As expected the $\mathrm{R}_{0}$ value vary for the two systems according to PBS-PFP/TPPS $\leq$ PBS-PFP-DPP. However, the efficiency of the porphyrin PL runs counter to expectation on the basis of Förster theory, since the copolymer PBS-PFP-DPP is the least efficient despite the larger $\mathrm{R}_{0}$ value ${ }^{72}$. As mentioned before, when we discussed the properties of the PBS-PFP-DPP, were discussed other factors than the Förster efficiency govern the copolymer PL efficiency ${ }^{72}$. Overall the values calculated for the Förster distance are comparable to what had been determined for the singlet-singlet Förster transfer, from fluorene-based polyelectrolytes and oppositely charged complexes and porphyrins 32,73 .

\section{Conclusions}

We have explored the mechanisms for energy transfer in two fluorene based conjugated polyelectrolytes (donor) systems, with on-chain porphyrin moieties and self-assembled with an anionic porphyrin bound electrostatically by $\mathrm{Ca}^{2+}$.

Investigation of the photophysical properties of the CPEs leads to the conclusion that the polymers are relatively free from aggregation in the solvent mixtures, $\mathrm{C}_{12} \mathrm{E}_{5}$ and water organic co-solvent.

Time-resolved experiments and steady state measurements have been conducted in solution to unravel the role of energy transfer on both systems. The energy transfer process in the PBS-PFP-DPP case should compete with other deactivaction processes, such as radiative decay of the singlet excitons photogenerated on the donor-acceptor conjugated chains and copolymer solution conformational changes. The existing difference between the overall energy transfer efficiency among the PBS-PFP-DPP copolymer and the selfassembled system is attributed to the porphyrin chromophore content within the polymer, that is not necessarily equal to the TPPS solution concentration. As observed by Morgado and co-workers ${ }^{69}$ the energy transfer efficiency values in a MEH-PPV porphyrin blend and in a MEH-PPV-porphyrin copolymer are similar only when the copolymer possesses the highest porphyrin concentration. Furthermore, the spatial extent, intermolecular separation and relative 
orientations of transition dipole densities on the donor and acceptor PFporphyrin copolymers determinate the rate of electronic excitation transfer, as observed for the cofacial and collinear orientations between the donor and the acceptor.

\section{Acknowlegments}

Financial support from FCT (Fundação para a Ciência e a Tecnologia) is acknowledge through the attribution of the Ph.D grants of ATM (SFRH/BD/36666/2007), SMAP (SFRH/BD/47022/2008) and CJPM (SFRH/BD/37652/2007). Dr. João Pina from the University of Coimbra is acknowledged for his excellent technical support in the TCSPC experiments. We thank the Evonik Science to Business Center, Marl Germany, for the photoelectron spectroscopy measurements.

\section{Bibliography}

(1) Moons, E.; J. Phys.: Condens. Matter, 2002, 14, 12235-12260.

(2) Hains, A. W.; Liang, Z.; Woodhouse, M. A.; Gregg, B. A.; Chem. Rev., 2010, $110,6689-6735$.

(3) Wen, Y.; Liu, Y.; Adv. Mater., 2010, 22, 1331-1345.

(4) Zöllner, M. J.; Frähmcke, J. S.; Elstner, M.; Jahn, U.; Jones, P. G.; Becker, E.; Kowalsky, W.; Johannes, H.-H.; Macromol. Chem. Phys., 2010, 211, 359-371.

(5) Zou, Y.; Najari, A.; Berrouard, P.; Beaupré, S.; Aïch, B. R.; Tao, Y.; Leclerc, M.; J. Am. Chem. Soc., 2010, 132, 5330-5331.

(6) Lei, T.; Cao, Y.; Fan, Y.; Liu, C.-J.; Yuan, S.-C.; Pei, J.; J. Am. Chem. Soc., 2011, 133, 6099-6101.

(7) Huang, F.; Zhang, Y.; Liu, M. S.; Jen, A. K.-Y.; Adv. Funct. Mater., 2009, 19, $1-10$.

(8) Perzon, E.; Zhang, F.; Andersson, M.; Mammo, W.; Inganäs, O.; Andersson, 
M. R.; Adv. Mater., 2007, 19, 3308-3311.

(9) Berton, N.; Lemasson, F.; Tittmann, J.; Stürzl, N.; Hennrich, F.; Kappes, M. M.; Mayor, M.; Chem. Mater., 2011, 23, 2237-2249.

(10) Wang, X.; Wang, H.; Yang, Y.; He, Y.; Zhang, L.; Li, Y.; Li, X.; Macromolecules, 2010, 43, 709-715.

(11) Huang, X.; Shi, Q.; Chen, W.-Q.; Zhu, C.; Zhou, W.; Zhao, Z.; Duan, X.-M.; Zhan, X.; Macromolecules, 2010, 43, 9620-9626.

(12) Ego, C.; Marsitzky, D.; Becker, S.; Zhang, J.; Grimsdale, A. C.; Müllen, K.; MacKenzie, J. D.; Silva, C.; Friend, R. H.; J. Am. Chem. Soc., 2003, 125, 437-443.

(13) Huang, J.; Li, G.; Wu, E.; Xu, Q.; Yang, Y.; Adv. Mater., 2006, 18, 114-117.

(14) Xu, Y.; Guan, R.; Jiang, J.; Yang, W.; Zhen, H.; Peng, J.; Cao, Y.; Journal of Polymer Science: Part A: Polymer Chemistry, 2008, 46, 453-463.

(15) Meng, G.; Velayudham, S.; Smith, A.; Luck, R.; Liu, H.; Macromolecules 2009, 42, 1995-2001.

(16) McNeill, C. R.; Greenham, N. C.; Adv. Mater., 2009, 21, 3840-3850.

(17) Wu, P.-T.; Bull, T.; Kim, F. S.; Luscombe, C. K.; Jenekhe, S. A.; Macromolecules, 2009, 42, 671-681.

(18) Campo, B. J.; Duchateau, J.; Ganivet, C. R.; Ballesteros, B.; Gilot, J.; Wienk, M. M.; Oosterbaan, W. D.; Lutsen, L.; Cleij, T. J.; de la Torre, G.; Janssen, R. A. J.; Vanderzande. D.; Torres, T.; Dalton Trans., 2011, 40, 3979 - 3988.

(19) Kraft, A.; Grimsdale, A. C.; Holmes, A. B.; Angew. Chem. Int. Ed. , 1998, 37, 402-428.

(20) Perepichka, I. F.; Perepichka, D. F.; Meng, H.; Wudl, F.; Adv. Mater., 2005, 17, 2281-2305.

(21) Nunzi, J.-M.; C. R. Physique, 2002, 3, 523-542.

(22) Dennler, G.; Scharber, M. C.; Brabec, C. J.; Adv. Mater., 2009, 21, 1-16.

(23) Beljonne, D.; Pourtois, G.; Silva, C.; Hennebicq, E.; Herz, L. M.; Friend, R. H.; Scholes, G. D.; Setayesh, S.; Müllen, K.; Brédas, J. L.; PNAS, 2002, 99, 10982 10987. 
(24) Scherf, U.; List, E. J. W.; Adv. Mater., 2002, 14, 477-487.

(25) Grimsdale, A. C.; Müllen, K.; Adv. Polym. Sci., 2008, 212, 1 - 48.

(26) Schwartz, B. J.; Annu. Rev. Phys. Chem., 2003, 54, 141-172.

(27) Abbel, R.; Grenier, C.; Pouderoijen, M. J.; Stouwdam, J. W.; Leclère, P. E. L. G.; Sijbesma, R. P.; Meijer, E. W.; Schenning, A. P. H. J.; J. Am. Chem. Soc., 2009, $131,833-843$.

(28) Wu, C.; Zheng, Y.; Szymanski, C.; McNeill, J.; J. Phys. Chem. C, 2008, 112, 1772-1781.

(29) Li, C.; Bo, Z.; Polymer, 2010, 51, 4273-4294.

(30) Dutta, P.; Rai, R.; Pandey S.; J. Phys. Chem. B, 2011, 115, 3578-3587.

(31) Li, B.; Xu, X.; Sun, M.; Fu, Y.; Yu, G.; Liu, Y.; Bo, Z.; Macromolecules, 2006, $39,456-461$.

(32) Pinto, S. M.; Burrows, H. D.; Pereira, M. M.; Fonseca, S. M.; Dias, F. B.; Mallavia, R.; Tapia, M. J.; J. Phys. Chem. B, 2009, 113, 16093-16100.

(33) Wang, X.; Wang, H.; Yang, Y.; He, Y.; Zhang, L.; Li, Y.; Li, X.; Macromolecules 2010, 43, 709-715.

(34) Lyons, B. P.; Jackson, R. J.; Wong, K. S.; Monkman, A. P.; Synthetic Metals, 2003, $135-136,367-368$.

(35) Virgili, T.; Lidzey, D. G.; Bradley, D. D. C.; Synthetic Metals, 2000, 111 $112,203-206$.

(36) Song, J.; Aratani, N.; Kim, P.; Kim, D.; Shinokubo, H.; Osuka, A.; Angew. Chem. Int. Ed., 2010, 49, 3617-3620.

(37) Kim, P.; Sung, J.; Uoyama, H.; Okujima, T.; Uno, H.; Kim, D.; J. Phys. Chem. B, 2011, 115, 3784-3792.

(38) Yoneda, T.; Saito, S.; Yorimitsu, H.; Osuka, A.; Angew. Chem. Int. Ed., 2011, 50, 3475-3478. 
(39) Liddell, P. A.; Gervaldo, M. G.; Bridgewater, J. W.; Keirstead, A. E.; Lin, S.; Moore, T. A.; Moore, A. L.; Gust, D.; Chem. Mater., 2008, 20, 135-142.

(40) Castriciano, M. A.; Romeo, A.; Angelini, N.; Micali, N.; Longo, A.; Mazzaglia, A.; Scolaro, L. M.; Macromolecules, 2006, 39, 5489-5496.

(41) Burrows, H. D.; Lobo, V. M. M.: Pina, J.; Ramos, M. L.; de Melo, J. S.; Valente, A. J. M.; Tapia, M. J.; Pradhan, S.; Scherf, U.; Macromolecules, 2004, 37, 74257427.

(42) Wong, K. F.; Bagchi, B.; Rossky, P. J.; J. Phys. Chem. A, 2004, 1085752 5763.

(43) Saini, S.; Srinivas, G.; Bagchi, B.; J. Phys. Chem. B, 2009, 113, 1817 - 1832.

(44) Hwang, I.; Scholes, G. D.; Chem. Mater. 2011, 23, 610 - 620.

(45) Jiang, H.; Zhao, X.; Schanze, K. S.; Langmuir, 2006, 22, 5541 - 5543.

(46) da Costa, J. L. T.; Silva, C. L.; Valente, A. J. M.; Pais, A. A. C. C.; Burrows, H. D.; RICI-2 Colloids and Interfaces, SPQ, Coimbra, 2007, p.533-537.

(47) Littler, B. J.; Miller, M. A.; Hung, C.-H.; Wagner, R. W.; O’Shea, D. F.; Boyle, P. D.; Lindsey, J. S.; J. Org. Chem., 1999, 64, 1391-1396.

(48) DiMagno, S. G.; Lin, V. S.-Y.; Therien, M. J.; J. Org. Chem., 1993, 58, 59835993.

(49) Zhou, X.; Shen, P.; Zhao, B.; Jiang, P.; Deng, L.; Tan, S.; Journal of Polymer Science Part A: Pol. Chemistry, 2011, 49, 2685-2692.

(50) Xu, X.; Chen, H.; Huo, E.; Cai, X.; Ying, Y.; Polymer Bulletin, 2008, 60, 7-14.

(51) Huang, X.; Zhu, C.; Zhang, S.; Li, W.; Guo, Y.; Zhan, X.; Liu, Y.; Bo, Z.; Macromolecules, 2008, 41, 6895-6902.

(52) Montalti, M.; Credi, A.; Prodi, L.; Gandolfi, M. T.; Handbook of Photochemistry, Taylor \& Francis, 2006. 
(53) Pina, J.; Melo, J. Seixas de; Burrows, H. D.; Maçanita, A. L.; Galbrecht, F.; Bünnagel, T.; Scherf, U.; Macromolecules, 2009, 42, 1710.

(54) Burrows, H. D.; Fonseca, S. M.; Silva, C. L.; Pais, A. A. C. C.; Tapia, M. J.; Pradhan, S.; Scherf, U.; Phys. Chem. Chem. Phys., 2008, 10, 4420-4428.

(55) Gouterman, M.; J. Mol. Spectrosc., 1961, 6, 138 - 163.

(56) Burrows, H. D.; Tapia, M. J.; Fonseca, S. M.; Pradhan, S.; Scherf, U.; Silva, C. L.; Pais, A. A. C. C.; Valente, A. J. M.; Schillén, K.; Alfredsson, V.; Carnerup, A. M.; Tomsic, M.; Jamnik, A.; Langmuir, 2009, 25, 5545 - 5556.

(57) Knaapila, M.; Almásy, L.; Garamus, V. M.; Pradhan, S.; Pearson, C.; Petty, M. C.; Scherf, U.; Burrows, H. D.; Monkman, A. P.; J. Phys. Chem. B, 2006, 110, 10248 $-10257$.

(58) Burrows, H. D.; Knaapila, M.; Monkman, A. P.; Tapia, M. J.; Fonseca, S. M.; Ramos, M. L.; Pyckhout-Hintzen, W.; Pradhan, S.; Scherf, U.; J. Phys. Cond. Matter, 2008, 20, 102410.

(59) Burrows, H. D.; Tapia, M. J.; Fonseca, S. M.; Valente, A. J. M.; Lobo, V. M. M.; Justino, L. L. G.; Qiu, S.; Pradhan, S.; Scherf, U.; Chattopadhyay, N.; Knaapila, M.; Garamus, V. M.; Appl. Mater. Interfaces, 2009, 1, 864-874.

(60) Dias, F. B.; Maçanita, A. L.; de Melo, J. S.; Burrows, H. D.; Güntner, R.; Scherf, U.; Monkman, A. P.; J. Chem. Phys., 2003, 118, 7119-7126.

(61) Burrows, H. D.; Fonseca, S. M.; Dias, F. B.; de Melo, J. S.; Monkman, A. P.; Scherf, U.; Pradhan, S.; Adv. Mater., 2009, 21, 1155-1159.

(62) Al Attar, H. A.; Monkman, A. P.; Adv. Funct. Mater., 2008, 18, 2498-2509.

(63) de Melo, J. S.; Sobral, A. J. F. N.; Gonsalves, A. M. d’A. R.; Burrows, H. D.; J. Photochem. Photobiol. A: Chemistry, 2005, 172, 151-160.

(64) Burrows, H. D.; Calvete, M. J. F.; da Costa, J. L. T.; Fonseca, S. M.; Marques, A. T.; Monteiro, C. J. P.; Pereira, M. M.; Pinto, S. M. A.; Scherf, U.; Valente, A. J. M. manuscript in preparation. 
(65) Monteiro, C. J. P.; Pereira, M. M.; Pinto, S. M. A.; Simões, A.V.C.; Sá, G. F. F.; Arnaut, L. G.; Formosinho, S. J.; Simões, S.; Wyatt, M. F., Tetrahedron, 2008, 64, 5132-5138.

(66) Fujitsuka, M.; Okada, A.; Tojo, S.; Takei, F.; Onitsuka, K.; Takahashi, S.; Majima, T.; J. Phys. Chem. B, 2004, 108, 11935-11941.

(67) Iqbal, R; Moratti, S. C.; Holmes, A. B.; Yahioglu, G.; Milgrom, L. F.; Cacialli, F.; Morgado, J.; Friend, R. H.; Journal of Materials Science: Materials in Electronics, 2000, 11, 97-103.

(68) Tapia, M. J.; Monteserín, M.; Costoyas, A.; Burrows, H. D.; Marques, A. T.; Pais, A. A. C. C.; Valente, A. J. M.; Mallavia, R.; Scherf, U.; Pinazo, A.; Pérez, L.; Morán, M. C.; Journal of Molecular Liquids, 2010, 156, 18-27.

(69) Morgado, J.; Cacialli, F.; Iqbal, R.; Moratti, S. C.; Holmes, A. B.; Yahioglu, G.; Milgrom, L. R.; Friend, R. H.; J. Mater. Chem., 2001, 11, 278-283.

(70) Turro, N. J.; Modern Molecular Photochemistry, University Science Books 1991.

(71) Lakowicz, J. R.; Principles of Fluorescence Spectroscopy, 3rd Edition, Springer 2006.

(72) Tan, C.; Atas, E.; Müller, J. G.; Pinto, M. R.; Kleiman, V. D.; Schanze, K. S.; J. Am. Chem. Soc., 2004, 126, 13685- 36949.

(73) Burrows, H. D.; Fonseca, S. M.; Dias, F. B.; de Melo, J. S.; Monkman, A. P.; Scherf, U.; Pradhan, S.; Adv. Mater., 2009, 21, 1155-1159. 